\title{
III-V Compounds-on-Si: Heterostructure Fabrication, Application and Prospects
}

\author{
Yu. B. Bolkhovityanov* and O. P. Pchelyakov \\ Institute of Semiconductor Physics, Siberian Branch of the Russian Academy of Sciences, 630090 Novosibirsk, Russian \\ Federation, Russia
}

\begin{abstract}
While silicon and gallium arsenide are dominant materials in modern micro- and nanoelectronics, devices fabricated from them still use $\mathrm{Si}$ and GaAs substrates only separately. Integrating these materials on the large and cheep Si substrate has been the subject of enormous research efforts for the past three decades. This review attempts to systematize and generalize the current understanding of the fundamental physical mechanisms governing the epitaxial growth of GaAs and related III-V compounds on Si substrates. Different kinds of bonding as a very promising non-epitaxial method for III-V thin film integration on Si substrate are reviewed. Basic techniques available for improving the quality of such heterostructures are described, and recent advances in fabricating of device-quality III-V-on-Si heterostructures and corresponding devices are also presented.
\end{abstract}

\section{INTRODUCTION}

Silicon is and will be the basic material for solid-state electronics. About $95 \%$ of all semiconductor devices are presently fabricated using silicon wafers. As a carrier, a Si wafer is undoubtedly advantageous due to its light weight, higher thermal conductivity, low cost, up to $300 \mathrm{~mm}$ substrate diameter and very mature technology. On the other hand, III-V compounds (and first of all, GaAs), following Si in the known list of most important semiconductor materials, are the major ingredients for optoelectronics and, due mainly to a considerably higher electron mobility, they are very suitable for very fast operation devices. It is only natural therefore that researchers all over the world wanted to combine these materials on a Si wafer for quite some time.

The first step on the way in this trend is obtaining highquality thin GaAs layers on Si wafers, the so-called artificial or alternative wafer platforms. Such GaAs-on-Si wafers are supposed to have a considerable market potential both for the replacement of an expensive GaAs wafer in fabrication of traditional devices (microwave devices, solar cells, photodetectors) and for monolithic integration of highperformance GaAs devices with high-density silicon integration circuits. The wish to realise these aims was a driving force for numerous investigations in both epitaxial growth of III-V compounds on $\mathrm{Si}$ wafers and elaboration of wafer bonding techniques of these compounds to Si.

\section{III-V-ON-SI BY EPITAXY}

\subsection{Direct GaAs-on-Si Epitaxy}

The first successful experiments in GaAs growth on $\mathrm{Si}$ wafers date back to the 80's of the last century (see e.g. [1-5]).

\footnotetext{
*Address correspondence to this author at the Institute of Semiconductor Physics, Siberian Branch of the Russian Academy of Sciences, 630090 Novosibirsk, Russian Federation; Tel: +7 383 3333286; Fax: +7 383 3333502; E-mail: bolkhov@isp.nsc.ru
}

Historically, the first experiments in GaAs growth on Si wafers have been conducted by means of growing this material directly on Si [1-13]. By the onset of the last decade of the $\mathrm{XX}^{\text {th }}$ century the basic problems were found out and laid down in the wide review by Fang et al. [14]. It is, first of all, the growth of polar semiconductor on a non-polar semiconductor leading to high density antiphase domains formation. The pure (001) silicon surface consists of, mainly, monoatomic steps on the surface of which $\mathrm{Si}$ atoms are arranged as dimers directed perpendicularly to each other on the neighbouring terraces. Passivation of such a surface with arsenic, i.e. covering Si surface with As monolayer — at the initial stage necessary for polar compound growth on the non-polar wafer - leads to the formation of As dimers directed also perpendicularly to each other on the neighbouring terraces. GaAs nucleus appeared on the neighbouring terraces will also be turned to each other at $90^{\circ}$ round the vertical axis. Imperfections of crystal structure turn up during their growth and coalescence, and they are called antiphase defects. This problem was successfully resolved using $\mathrm{Si}$ wafers misoriented from the singular plane (001) by 4-6 arc degrees (see e.g. [7]). On such a Si wafer surface two-atomic steps develop, and $\mathrm{Si}-\mathrm{Si}$ dimers have the same orientation forming the so-called single domain surface. As a consequence, in the As monolayer deposited onto Si surface before GaAs growth onset, arsenic dimers also have identical orientation and, after applying $\mathrm{Ga}, \mathrm{GaAs}$ crystallites of one sign are formed.

Other problems turned out more serious. Dislocation density in GaAs film reaches the values of $10^{9}-10^{10} \mathrm{~cm}^{-2}$ due to the difference between the film and wafer lattice parameters close to $4 \%$ in the system of $\mathrm{GaAs} / \mathrm{Si}$. The difference in thermal expansion coefficients $\left(6.63 \times 10^{-6} \mathrm{~K}^{-1}\right.$ and $2.3 \times 10^{-6} \mathrm{~K}^{-1}$ for $\mathrm{GaAs}$ and $\mathrm{Si}$, respectively) also promotes the formation of a big number of dislocations and appearing of cracks in the GaAs film during cooling. These problems are still a serious obstacle for epitaxial growth of high quality GaAs films less than one micron thick on Si wafers. 
The mechanism of new phase formation via islands (three-dimension, 3D growth) is one of the fundamental reasons for a big number of defects in GaAs/Si films at the initial stage of epitaxial growth. According to Asai et al. [15], the reflection high-energy electron diffraction (RHEED) turned to spotty that corresponds to the growth onset by the island mechanism - already after applying GaAs film onto $\mathrm{Si}$, average thickness being 1 monolayer, and even more obvious when it is 2 monolayers thick. Typical picture of RHEED spotty patterns just at the initial part of GaAs growth is presented in Fig. (1). We can see the spotty patterns which are connected by tension bars reflecting the facet sides appearing. Investigation of such a surface using atomic-force microscopy (AFM) is indicative of the appearance of islands having density of $10^{11} \mathrm{~cm}^{-2}$. GaAs/Si islands have the ratio of height to the lateral size being close to $1 / 2$ at the initial growth stage $[16,17]$. Later on, as an average GaAs layer thickness increases, the islands shape changes slightly, and it can be observed in the papers by Fang et al. [14] and Tsai et al. [16] on transmission electron microscopy (TEM) images of cross-sections of such structures and also on AFM images [17, 18]. Recently Usui et al. [17] have shown that hemispherical and dislocated GaAs islands are grown on the Si substrate as early as only 4 GaAs monolayers at $400{ }^{\circ} \mathrm{C}$ are supplied.

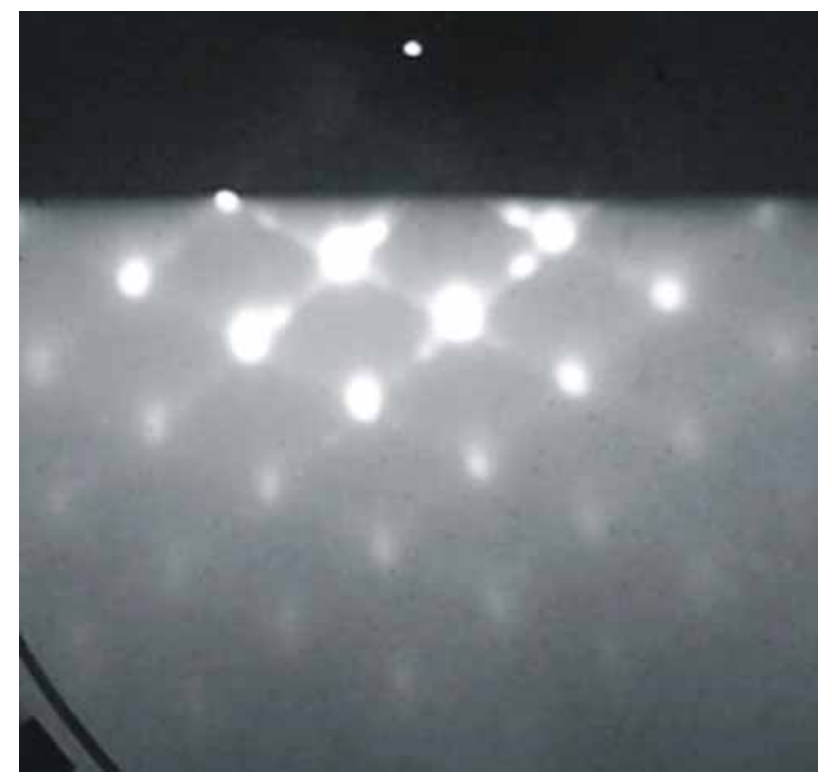

Fig. (1). RHEED patterns of GaAs/Si epitaxial growth at the initial stage: GaAs average thickness is about $1 \mathrm{ML}$. (This picture has been provided by M. A. Putuato).

Different methods and techniques that allow us to decrease the dislocation density at the by-surface GaAs layer region down to $\sim 10^{6} \mathrm{~cm}^{-2}$ have been worked out for thicker $\mathrm{GaAs} / \mathrm{Si}$ layers. It is, first of all, thermal cycle annealing (TCA) $[10,11,13]$ and also using lower temperatures at the initial part of GaAs growth- the so-called two-step growth $[6,18-25]$. The first step is either some nanometers (or tens of nanometers) of GaAs grown at low temperatures or molecular enhanced epitaxy (MEE) by alternating Ga and As. Solid-phase crystallisation of amorphous GaAs layer can also be referred to the first step. The basic part of GaAs layer is then grown under the conditions standard for this material. Insertions in $\mathrm{GaAs}$ layer volume as ultra-thin epitaxial layers of Si, InGaAs strained material and also strained superlattices $[8,12,26]$ actively initiate annihilation of threading dislocations (TD).

The general structural quality of GaAs films grown on $\mathrm{Si}$ (001) can be estimated with X-ray rocking curves from the film in planes (004) reflection. Full width on a half maximum (FWHM) directly depends on defects concentration in the film. Measured by different authors, FWHM values on $\mathrm{GaAs}$ films of various thicknesses grown directly on the $\mathrm{Si}$ wafer having orientation (001) are shown in Fig. (2). These dots array is pointed out as a shaded area. A big diversity of half-width values for the same GaAs film thicknesses is observed. Dashed downward arrows show a considerable improvement of film structural characteristics for one and the same thickness when using TCA [19, 27-32]. Intermediate layer insertions with another lattice parameter also contributed to FWHM decrease (insertion Si [29], insertion InGaAs [31]). Li et al. grew GaAs epilayers on a $\mathrm{SiO}_{2}$-patterned silicon substrate [33]. They have shown that dislocations in such heterostructures can be largely eliminated by trapping on vertical dielectric sidewalls. As one can see in Fig. (2a) the value of FWHM taken from this work is finding in the bottom part of the shaded area.

The theoretical dependence (dashed line) of FWHM on perfect (dislocation-less) film thickness whose value decreases only by an increasing number of the perfect crystal reflecting planes is also depicted in Fig. (2). GaAs epitaxial films being grown on Si wafer can not get closer to this dependence in their structural perfection as their pseudomorphic and, respectively, defect-less state is possible only at the stage of separate nucleus. After the beginning of GaAs film plastic relaxation with the formation of a big number of defects at the interface, FWHM can not be close to the theoretical dependence - as is seen in Fig. (2). Fig. (2b) is a simplified version of Fig. (2a) that allows us to compare $\mathrm{GaAs} / \mathrm{Si}$ experimental results to FWHM values for the films obtained in another way. If we assign only the best results from papers in which GaAs films grown directly on $\mathrm{Si}$ were investigated these results hit in the hatched oval in Fig. $(\mathbf{2} \boldsymbol{b})$.

There are some other ways of putting GaAs on Si. Thus, the FWHM value for GaAs film being $2.5 \mu \mathrm{m}$ grown on the Si wafer over the buffer Ge/GeSi taken from Luo et al. [34] is shown in Fig. (2). This value, equal to 120 arc sec. is currently the lowest for the corresponding GaAs film thickness epitaxially grown on the $\mathrm{Si}$ wafer. In this $\mathrm{GaAs} / \mathrm{Ge} / \mathrm{GeSi} / \mathrm{Si}$ heterostructure the basic dislocation array, responsible for the compensation of lattice parameter misfit for GaAs and $\mathrm{Si}$, is located inside the buffer GeSi layer and it only slightly affects the widening of X-ray rocking curves for the GaAs film. Tanoto et al. [35] grew GaAs on Ge/Si platform using MEE method on the initial part of the growth. Then, a standard GaAs MBE growth process was used to grow a structure comprising a 250-nm thick GaAs, 6-nm-thick $\mathrm{In}_{0.2} \mathrm{Ga}_{0.8} \mathrm{As}$ single quantum well, and a 100 -nm-thick GaAs cap layer. As authors have reported the FWHM of the layer peak of the GaAs film about $0.35 \mu \mathrm{m}$ thick with inserted InGaAs thin layer was 160 arc sec. As can be seen in Fig. 

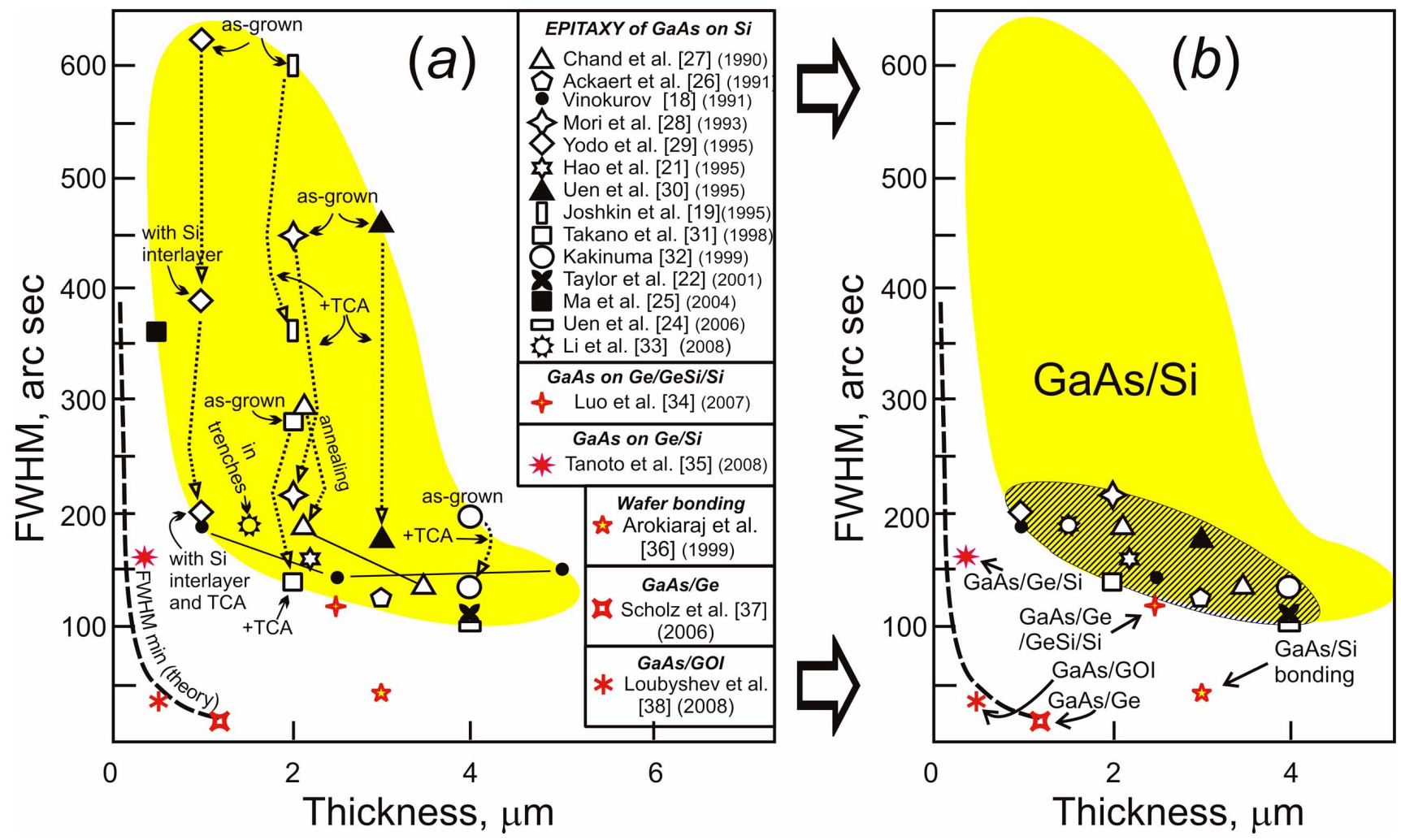

Fig. (2). Full width at a half-maximum of the (004) GaAs X-ray peak (FWHM) according to different authors in depending on GaAs film thickness. Dashed line is the theoretical curve for pseudomorphic defect-less film. (a) - experimental dot array for GaAs films, grown directly on $\mathrm{Si}$, is inside of the shaded area. Intermediate experimental dots of this array and also references are omitted in (b) for easier perception and comparison with other data. Only the best results from papers in which GaAs films grown directly on Si were investigated are preserved in the hatched oval in Fig. (2b). Red points (color on line) are for the GaAs films whose direct growth on Si was avoided.

(2), such value of FWHM is also minimal in comparison with FWHMs for GaAs films directly grown on $\mathrm{Si}$.

There are non-epitaxial methods of thin GaAs film organisation on the Si wafer- the so-called wafer bonding technique. According to this technology, the GaAs film grown on the GaAs wafer is separated from this wafer and transferred to the Si wafer (the corresponding methods are considered in more detail in Chapter 3). In this case there are no defects inevitably appearing in the film under heteroepitaxy, and the FWHM value is determined by imperfections occurring during homoepitaxial GaAs/GaAs growth and bonding to the Si wafer. Thus, Arokiaraj et al. [36], having realised the bonding of GaAs film to the Si wafer and having removed the GaAs wafer using selective etching, note that the FWHM of such a $3 \mu \mathrm{m} \mathrm{GaAs}$ film is equal to $44 \mathrm{arc} \mathrm{sec}$. (Fig. 2). This value is minimal for all GaAs/Si films some microns thick. The best results in FWHM of GaAs films are observed when they are grown on the Ge or GOI wafers (Geon-Insulator, - Ge on Si by bonding, for more details on such platform see Chapter 3). Thus, the FWHM values of GaAs/Ge and GaAs/GOI borrowed from Scholtz et al. [37] and Loubyshev et al. [38] are hit on or near of the theoretical dependence (Fig. 2).

Therefore, comparison of FWHM values for GaAs films grown directly on Si wafers (hatched oval in Fig. $2 \boldsymbol{b}$ ) to the results obtained on $\mathrm{GaAs} / \mathrm{Ge}(\mathrm{GeSi}) / \mathrm{Si}$ platforms and, especially on GaAs/Ge, GaAs/GOI and GaAs-on-Si by bonding are in favour of the methods in which the difference in lattice parameters between GaAs film and the wafer is either practically absent or was overcome by wafer bonding.

\subsection{GaAs-on-Si Growth Through Buffer Layers}

As is seen in Fig. (2), the least FWHM value for the GaAs films of a certain thickness epitaxially deposited on $\mathrm{Si}$ is observed under the buffer $\mathrm{Ge}$ or $\mathrm{Ge} / \mathrm{GeSi}$ layer introduction between the film and the wafer. The method of fabricating of $\mathrm{Ge} / \mathrm{GeSi} / \mathrm{Si}$-related artificial wafer - where $\mathrm{GeSi}$ is an intermediary layer with a changing lattice parameter that ends in pure Ge, - is the most developed. GaAs and Ge have close values of lattice parameters and thermal expansion coefficients. Earlier investigations in growing perfect GaAs films on Ge wafers showed that antistructural defects and antiphase borders $[39,40]$ were the basic imperfections, and their density was reduced to zero by a certain wafer deviation at some degrees from (001) orientation [41, 42]. As can be seen in Fig. (2), the FWHM value for GaAs onto Ge is close to the theoretical one. Therefore, it was logical to implement $\mathrm{GaAs}$ growth on $\mathrm{Si}$ wafers through buffer layers having pure Ge on their surface.

The founding research in fabrication of GeSi buffer on $\mathrm{Si}$ layers was published in 1991, Fitzgerald et al. [43]. It was reported on $\mathrm{Ge}_{x} \mathrm{Si}_{1-x} / \mathrm{Si}(001)$ film growth ( $x$ equal to $\sim 0.5$ ) with TD density not more than $2 \times 10^{6} \mathrm{~cm}^{-2}$. The following problems were revealed at already this stage: to fabricate GeSi films with the above-mentioned density, the gradient of Ge composition must not to exceed $10 \%$ of Ge per micron of 


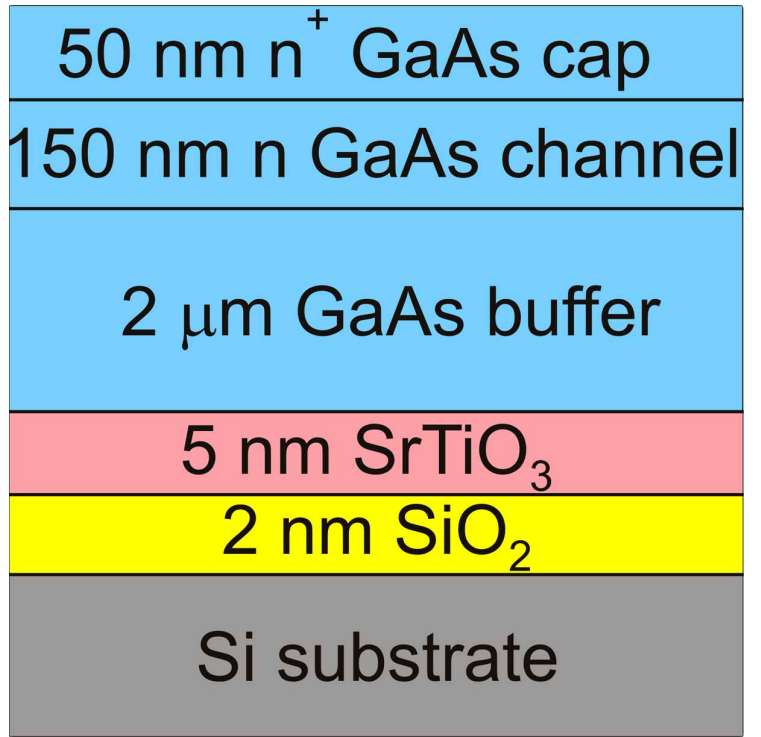

Fig. (3). Scheme of GaAs/STO/Si heterostructure according to Eisenbeiser et al. [64].

buffer layer thickness. It led to a big material consumption and the necessity for high growth temperatures $\left(\sim 900{ }^{\circ} \mathrm{C}\right)$ to ensure the acceptable heterostructure growth cycle time. High growth temperature, in its turn, contributed to a considerable increase of roughness of the final product surface that reached hundreds of nanometers [44]. The problem of surface roughness was partially resolved using $\mathrm{Si}$ wafers misorinted a few degrees from exact orientation (001) and chemical polishing of film surface [45]. Simultaneously, the composition of buffer $\mathrm{Ge}_{x} \mathrm{Si}_{1-x}$ layer was achieved being equal to $x=1$, i.e. the aim of film growth with a $100 \%$ Ge content was achieved. Having applied chemical polishing of $\mathrm{Ge}_{x} \mathrm{Si}_{1}$ ${ }_{x} / \mathrm{Si}(001)$ heterostructure at the intermediary growth stage, $x$ $=0.5$, with further GeSi buffer layer on-growth till pure Ge, the authors [46] demonstrated the possibility of fabricating artificial $\mathrm{Ge} / \mathrm{GeSi} / \mathrm{Si}(001)$ wafers with $\mathrm{TD}$ density in top $\mathrm{Ge}$ layer not more than $2 \times 10^{6} \mathrm{~cm}^{-2}$. The basic achievements of this method in fabrication of field effect transistors (FETs) with strained $\mathrm{Si}, \mathrm{GeSi}$ and Ge channels were published in review of Lee et al. [47]. GaAs film growth on $\mathrm{Ge} / \mathrm{GeSi} / \mathrm{Si}(001)$ platform and investigation of their properties became a natural expansion of using such a platform [48].

To date dislocation density in the functional part of epitaxial GaAs film can be decreased down to $10^{6} \mathrm{~cm}^{-2}$ only using gradient buffer GeSi layers. Respectively, the life time of minority carriers in GaAs (heterostructures of AlGaAs/GaAs/AlGaAs type grown on platform Ge/GeSi/Si) reached the value exceeding $10 \mathrm{~ns}$ [49]. Such high structural parameters of $\mathrm{GaAs} / \mathrm{Ge} / \mathrm{GeSi} / \mathrm{Si}$ platform enabled to fabricate a number of devices working on the minority carriers: solar cells, LEDs and injection lasers. By the present, all the basic device types earlier implemented in GaAs/GaAs and $\mathrm{GaAs} / \mathrm{Ge}$ heterostructures have also been fabricated with GaAs/GeSi/Si: solar cells [49-53], LEDs and lasers [54-58] (including also laser-PIN diode-like optical connections [59]), transistors [60]. The major contribution to this trend belongs to a group of Massachusetts Technological Institute headed by Fitzgerald [49-52, 54, 55, 57-60].

It is worth focusing on one more possibility of growth that of growing $\mathrm{GaAs} / \mathrm{Si}$ through the intermediate $\mathrm{SrTiO}_{3}$ (STO) layer. Such a way of growing GaAs was first announced in 2001 [61]. The earlier worked out methods for epitaxial deposition of STO insulator onto Si [62] was used for GaAs epitaxial growth over this insulator [63, 64]. STO growth was initiated with combined $\mathrm{Sr}$ and $\mathrm{Ti}$ deposition at oxygen ambient atmosphere at wafer temperature in the range of $200-400{ }^{\circ} \mathrm{C}[62,65]$. The $\mathrm{GaAs} / \mathrm{SrTiO}{ }_{3} / \mathrm{Si}$ heterostructure is schematically presented in Fig. (3). The $\mathrm{SiO}_{2}$ layer located between STO and Si is supposed to form after STO growth as a result of oxygen diffusion in $\mathrm{Si}$ at a certain temperature and can be used as an insulator separating the epitaxial structure from the wafer. It was reported on high qualities of grown heterostructures: dislocation density in GaAs was about $10^{5} \mathrm{~cm}^{-2}$, surface roughness mean-square value was about $0.9 \mathrm{~nm}$, antiphase domains were absent. Electron mobility in $\mathrm{GaAs} / \mathrm{SrTiO}_{3} / \mathrm{Si}$ was $94 \%$ from that of control GaAs/GaAs sample [64].

It was reported in [63] that $\mathrm{GaAs} / \mathrm{STO} / \mathrm{Si}$ heterostructures of device quality were grown on Si wafers 200 and $300 \mathrm{~mm}$ in diameter with molecular beam epitaxy (MBE) method at "Motorola Inc." laboratories. FETs fabricated on such heterostructure showed optimistic results: after 800 hours of operation at $200{ }^{\circ} \mathrm{C}$ the channel current degradation was $1.2 \%$ in sample GaAs/STO/Si. Chediak et al. [66], analysing these experiments, came to the conclusion that the authors of $[63,64]$ could successfully fabricate the device quality GaAs-on-Si films. However, the mechanisms responsible for the perfect GaAs film growth in GaAs/STO/Si configuration were not revealed, and our search over databases did not found any continuation of this work and parallel investigations in this trend by other researchers.

Dislocations are the basic defects worsening the device parameters on GaAs/Si. The most significant and replicated data on their least density in such epitaxial heterostructures are close to value $10^{6} \mathrm{~cm}^{-2}$. For transistors operating on majority carriers, a high dislocation density manifests itself in reduced electron (or hole) mobility, whereas minority-carrier devices (solar cells, light diodes, and injection lasers) are more sensitive to these defects. Dislocation density in such structures should be less than $10^{6} \mathrm{~cm}^{-2}$. As already noted earlier, Motorola-produced FETs based on GaAs/STO/Si heterostructures MBE-grown on Si substrates have very similar properties to reference $\mathrm{GaAs} / \mathrm{GaAs}$ samples [62-64]. At the same time, lasers made on $\mathrm{GaAs} / \mathrm{Ge} / \mathrm{GeSi} / \mathrm{Si}$-like platform with dislocation density equal to $2 \times 10^{6} \mathrm{~cm}^{-2}$ in GaAs were functional for not more than 4 hours [55].

In [67] it is reported on InGaAs/InAlAs/GaAs/Si heterostructure growth, on which FETs with quantum well $\mathrm{In}_{0.7} \mathrm{Ga}_{0.3} \mathrm{As}$ were fabricated. The buffer layer general thickness was $3.2 \mu \mathrm{m}$ at $2 \mu \mathrm{m}$ GaAs. According to the authors, TD density was not tested in the channel area on the structure's cross-section, i.e. it was less than $10^{8} \mathrm{~cm}^{-2}$. TD density, obviously, considerably decreases in the buffer InAlAs layer. These heterogeneous III-V transistors on silicon substrate show performance characteristics equal to those previously 


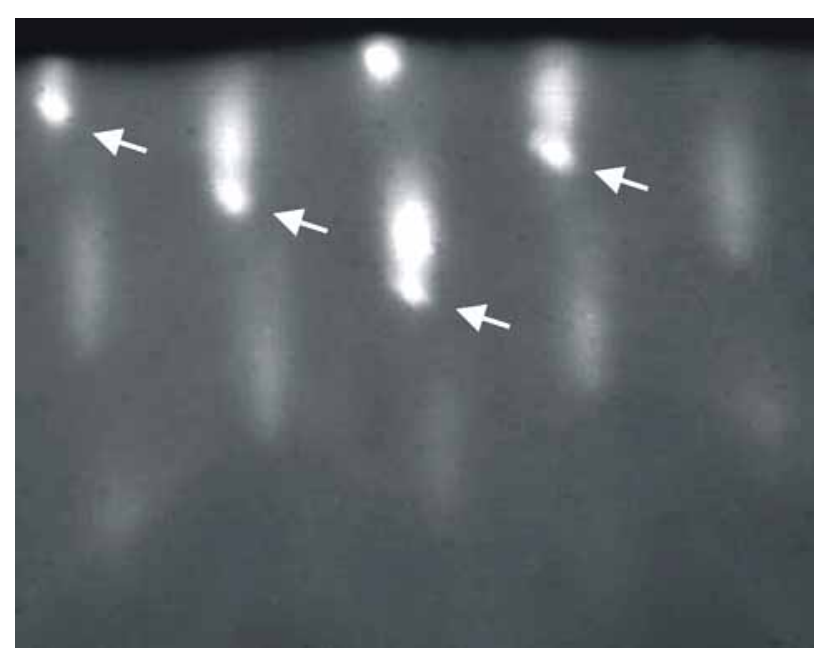

Fig. (4). RHEED patterns for the initial growth of GaP-on-Si. 4 monolayers of $\mathrm{GaP}$ are grown by MEE [71].

achieved on pseudomorphic $\mathrm{In}_{0.7} \mathrm{Ga}_{0.3} \mathrm{As}$ HEMTs on InP substrate.

Despite certain successful achievements in device fabrication based on GaAs and other III-V compounds grown on $\mathrm{Si}$ wafers, the solution for the problem of integrating GaAs optoelectronics and traditional $\mathrm{Si}$ integrated circuits on one substrate by growing GaAs films on Si wafers is still open. A big distance in thickness between GaAs and Si surfaces exceeding $10 \mu \mathrm{m}$, when using graded $\mathrm{Ge} / \mathrm{GeSi}$ buffers on $\mathrm{Si}$ wafers, is a serious barrier for using high-resolution lithography methods for connects between $\mathrm{Si}$ and III-V neighbours on the wafer. Therefore, researchers are now more focused on non-epitaxial bonding methods for heterogeneous materials that allow making them closer to each other at the distance less than 1 micron without any vivid worsening of their structural perfection.

\subsection{GaP-on-Si Epitaxy}

\subsubsection{Initial Stages}

Epitaxial $\mathrm{GaP}$ films on $\mathrm{Si}$ wafers are used as the first step in the transfer from $\mathrm{Si}$ to GaAs [68, 69], and also they are important proper as a basic element for different device applications [70]. A comparatively small difference between $\mathrm{GaP}$ and $\mathrm{Si}(0.37 \%)$ lattice parameters is a reliable factor. However, detailed studies of RHEED-assisted GaP-on-Si (001) initial growth stages showed that obtaining a perfectly continuous GaP layer at the initial growth stage is the main problem here (just as in $\mathrm{GaAs} / \mathrm{Si}$ ). Practically all researchers report that RHEED patterns show the formation of spotty reflections that correspond to $3 \mathrm{D}$ growth, right after the beginning of GaP-on-Si epitaxial growth. An example of such tendency is presented in Fig. (4) where the bright spots in the base of reflexes are seen [71].

The difference between $\mathrm{GaP}$ and $\mathrm{Si}$ lattice parameters increases with temperature and is already equal to $0.5 \%$ at $\mathrm{T} \sim 400{ }^{0} \mathrm{C}$. Critical film thickness at which introduction of misfit dislocations (MDs) is energetically efficient and plastic relaxation of $\mathrm{GaP}$ layer becomes possible does not exceed $20 \mathrm{~nm}$ for temperatures $400-500{ }^{0} \mathrm{C}$ in accordance to Mat- thews and Blakeslee [72] model. Thus, when the GaP film thickness exceeds this value and there is a sufficient number of MDs centres, its plastic relaxation will begin. Under ordinary regimes, in which the GaP-on-Si island growth is realised, the faceted film surface (after islands coalescence) is an active source of dislocations.

It is possible to point out some research papers significant for understanding the peculiarities of GaP-on-Si(001) [70, 73-80] growth. Continuous, supposedly pseudomorphic at their initial stage $\mathrm{GaP} / \mathrm{Si}$ films, could be observed only when grown with metal-organic chemical vapour deposition (MO CVD) method [81, 82]. The following can be referred to the proofs in these papers in favour of GaP films of possible pseudomorphic state: absence of defects in cross-section TEM images of films $90 \mathrm{~nm}$ thick observed in work of Soga et al. [81]; the additional periodic peaks seen on the GaP film X-ray rocking curves - so called thickness fringes resulted in report of Kunert et al. [82]. Presence of hydrogen in the reactor atmosphere under MO CVD growth is, obviously, a factor contributing to $\mathrm{GaP} / \mathrm{Si}$ film surface planarisation at its initial growth stages.

Takagi et al. [79] note that the $\mathrm{Si}(001)$ phosphorstabilised surface is chemically passive and, even at the initial stage of GaP monolayer deposition, there is a tendency to $\mathrm{GaP}$ island formation. Nevertheless, as the authors mention, dislocations were introduced in the continuous layer under $\mathrm{Ga}$ and $\mathrm{P}$ monolayer alternation growth (MEE), and their generation was not found at the stage of separate islands.

\subsubsection{General Structural Perfection}

The two-step growth [74, 76, 78], TCA [74] and also using MEE methods [73, 79, 83] led to a considerable improvement in characteristics of GaP-on-Si films. Results of different authors in FWHM dependence on GaP film thickness for the $\mathrm{GaP} / \mathrm{Si}$ are demonstrated in Fig. (5). A big range of data within film thickness to $0.5 \mu \mathrm{m}$ is observed. This fact confirms the key role of the initial stage of film formation. The theoretical dependence of FWHM for perfect GaP films (dashed curve) is presented in the same Fig. (5) allowing the crystal perfection of real films to be estimated. The fact of super low values of FWHM in works by Sadeghi and Wang [73] and $\mathrm{Yu}$ et al. [70] for thicknesses 0.2 and $0.4 \mu \mathrm{m}$, respectively, is outstanding. These values are pointed out in dashed oval in Fig. (5). For the left point (Sadeghi and Wang [73], film thickness $0.2 \mu \mathrm{m}$ ) one can suppose that this film is close to the pseudomorphic defect-less state and, therefore, FWHM has a small value close to that of theoretical. As a proof for the existence of such films, we used the data from Kunert et al. report [82], in which the thinnest GaP-on-Si films ever reported were studied by X-ray diffractometry. It is seen from Fig. (5) that these values practically coincide with the theoretical dependence, and it indicates the absence of defects in these films. This fact proves the possibility of growing a continuous defect -free pseudomorphic GaP-on$\mathrm{Si}(001)$ layer. Nevertheless, after the GaP film exceeds some thickness, introduction of MDs becomes inevitable. As is shown in the Fig. (5), the FWHM of the thicker $(0.5 \mu \mathrm{m})$ GaP film from Sadeghi and Wang [73] (experimental dots of these authors are joined with a dotted line in Fig. 5) consid- 


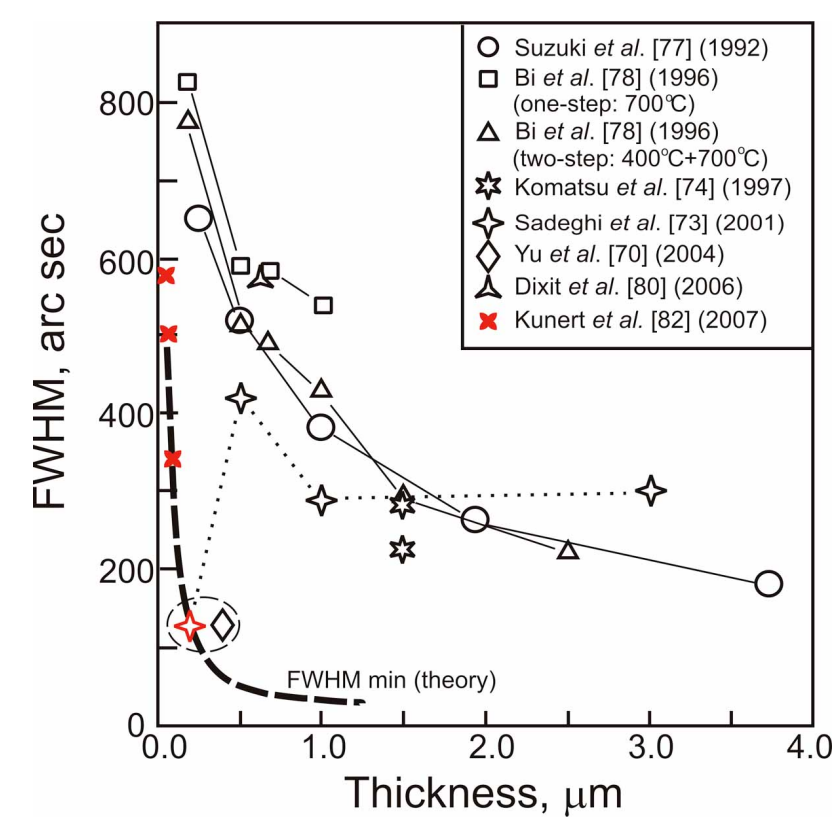

Fig. (5). Full width at a half-maximum of the (004) GaP X-ray peak versus the thickness of a $\mathrm{GaP}$ film on a $\mathrm{Si}$ substrate as presented by various authors. Red points (color on line) hit on the theoretical curve for pseudomorphic defect-less film.

erably increased becoming close to the basic data array for this thickness.

In Fig. (5), the right point of the dashed oval (film thickness $0.4 \mu \mathrm{m}$ ), on $\mathrm{Yu}$ et al. [70] assertion, corresponds to the completely relaxed state. Such a film must inevitably have a certain number of misfit dislocations-like defects and, nevertheless, its FWHM is 130 arc sec. which is the least value published for these GaP/Si thicknesses and that of close to the theoretical one. Explanation of such a difference from the data of other research papers lacks the analysis of such film structural characteristics. However, the appearance up of such parameters should be taken into account.

\section{NON-EPITAXIAL III-V-ON-SI TECHNIQUES (BONDING)}

The generic term 'wafer bonding' refers to transfer of bulk or thin-film GaAs (as well as other III-V compounds) to various, primarily $\mathrm{Si}$, substrates. Direct bonding of two solid bodies can be carried out even at room temperature by compression of specularly polished plane and totally pure surfaces. The conjoint surfaces interact at the atomic level due to Van der Waals forces. A profound history of such a contact can be found in review of Gösele et al. [84]. Thorough processing of conjoint surfaces, including their planarisation, minimisation of roughness value and thorough cleaning to remove any organic and metallic contaminations from the wafer surface [85-87] are necessary for direct bonding of two surfaces. The other bonding type is using high-temperature "sticking" of one solid body to the other by applying glasslike coating on both surfaces being bonded with further compression at the temperature of glass softening. In semiconductor technology, such bonding was first carried out by Antipas and Edgecumbe [88]. Heterostructure GaAs/AlGaAs was bonded to the glass wafer to fabricate a GaAs-based transmission photocathode. GaAs wafer was removed, and thick glass was used as a transparent handle wafer for GaAs/AlGaAs-like device heterostructure.

For the next years, different media for bonding of two heterogeneous materials were elaborated: $\mathrm{SiO}_{2}-\mathrm{SiO}_{2}$ [89, 90], borophosphorosilicate glass (BPSG) with different forms of coating - to those from liquid phase [91, 92], $\mathrm{SeS}_{2}-$ $\mathrm{SeS}_{2}$ [36], applying a thin viscous layer on both conjoined substrates with the centrifugal method from solutions based on silane $(\mathrm{Si}-\mathrm{OH})$ and methyl $\left(\mathrm{CH}_{3}\right)$ polymers solved in alcohol-aceton mixture [93, 94]. The bases of bonding technology for different semiconductor materials can be found in review of Gösele and Tong [95].

The key element in the whole technological chain of bonding a thin film to the handle wafer is working out the methods for donor wafer selective "rejection" or exfoliation following the bonding. One way involves the incorporation of stop layers into the bonding structure. A modern scheme of a GaAs film or a more complicated heterostructure transfer, e.g. laser structure, over to a massive $\mathrm{Si}$ wafer is displayed in Fig. (6). The transferred heterostructure and $\mathrm{Si}$ wafer (Fig. $6 \boldsymbol{a}$ and $\mathbf{6} \boldsymbol{b}$ ) are coated with an oxide layer and bonded at a certain pressure and oxide softening temperature (Fig. 6c). Stop layer in this case is AlGaAs film with a big Al content. It is grown directly on GaAs before the main heterostructure and locks the GaAs wafer etching. GaAs wafer (Fig. $6 \boldsymbol{d}$ ) and then also the stop layer are etched and, in position of Fig. (6e) (dashed oval) we have a new artificial wafer. Then the GaAs layer is either thinned and smoothed by chemical-mechanical polishing till the required thickness and surface smoothness (Fig. $6 f_{1}$ ) or an additional epitaxial growth of a new GaAs layer (Fig. $\boldsymbol{~}_{\mathbf{2}}$ ) is possible. In all the cases of such artificial GaAs/Si wafer organisation, the donor GaAs wafer is eliminated by etching, and it, naturally, makes such a technology considerably more expensive. Nevertheless, non-epitaxial bonding techniques give us a new degree of freedom allowing creating good quality combinations of materials which could not be realised earlier by single epitaxial growth.

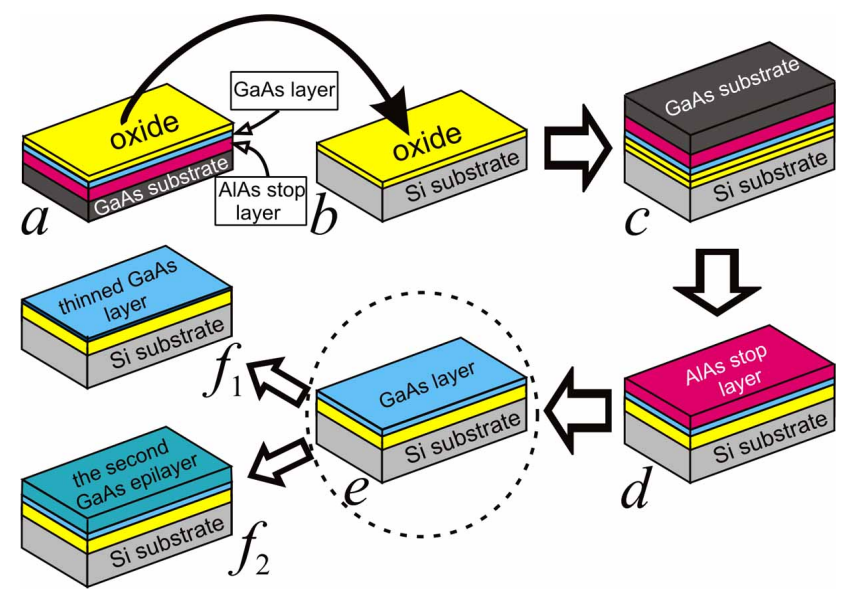

Fig. (6). Schematic of fabricating an artificial GaAs/Si substrate by the wafer bonding method. 


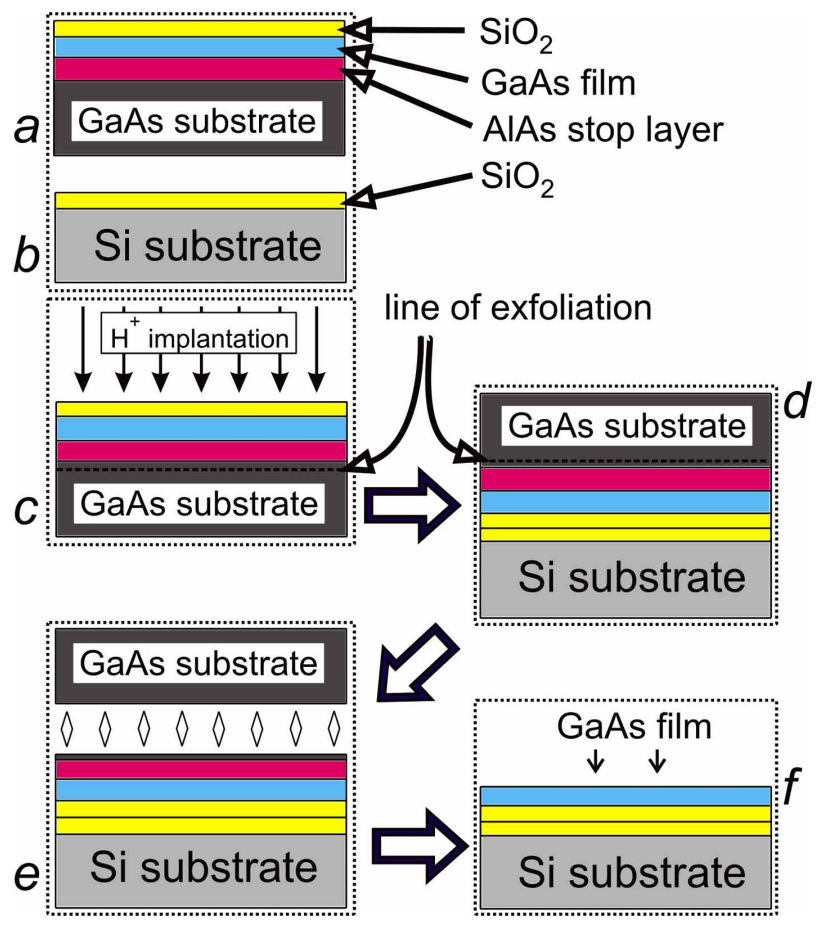

Fig. (7). Detachment (shot-off) scheme for the basic part of donor GaAs wafer using Smart $\mathrm{Cut}^{\mathrm{TM}}$ technology.

Another way is exfoliation of the main part of GaAs donor wafer based on the Smart $\mathrm{Cut}^{\mathrm{TM}}$ technology which was worked out earlier for fabrication of SOI (silicon-oninsulator) [96] wafers. The scheme of such exfoliation is presented in Fig. (7). Just as earlier (Fig. 6), the handle and donor wafers are coated with a thin oxide layer, e.g. $\mathrm{SiO}_{2}$ (Fig. 7a, b). Then, a layer of $\mathrm{H}$ or He bubbles (Fig. 7c) is made in the donor wafer at a certain depth with the ion bombardment method. After wafer bonding (Fig. 7d) the exfoliation (Smart $\mathrm{Cut}^{\mathrm{TM}}$ technology) is realised under heating (Fig. 7e). Such exfoliation of the basic part of a donor wafer from that of Si was used for both GaAs and InP [90, 97-99]. After this procedure, the surface of the structure's transferred part is coarse and needs chemical polishing. The stop layer presented in the Fig. (7) considerably facilitates the task. III-Vrelated device heterostructures are grown either on donor $\mathrm{GaAs}$ or InP wafers till bonding them to the Si wafer (e.g. laser heterostructures [100-104]) and then, reversed sequence of epitaxial layers is necessary, - or they are grown on the III-V layer left on Si after the bonding and exfoliation of the donor wafer. GaAs or InP wafers are considerably smaller in their diameters compared to those of Si. Therefore, a more perspective way of GaAs-on-Si film fabrication is epitaxial growth of this material on Ge-on-Si platforms. The method of bonding the donor $\mathrm{Ge}$ wafer to $\mathrm{Si}$ and further exfoliation of Ge layer based on the well-known Smart Cut ${ }^{\mathrm{TM}}[105,106]$ technology is analogous to that described above. In [107] it is reported on the fabrication of GOI platforms on $\mathrm{Si}$ wafers of 100-200 mm in diameter, with Ge films being from 200 to $50 \mathrm{~nm}$ thick.

Let us point out the advantages of Ge-related wafers over those of GaAs under the growth of III-V-related heterostruc- tures on them: high crystal perfection, higher mechanical strength, big diameters [108]. Earlier, these factors led to a wide use of Ge wafers in growing GaAs/Ge solar cells for telecommunication satellites [109], and they also make Ge a viable competitor for GaAs-related devices different from solar cells. High Ge-on-Si film perfection in GOI-like structures and their electrical isolation from the handle wafer contributed to the intensification of research in the methods of Ge-on-Si structures fabrication and to their diverse device applications (e.g. [110-112]).

GOI wafers are expected to be a promising platform for growing different III-V-based device structures. The work of Thomas et al. [113] proves it as an example. According to the authors, they first demonstrate the growth, fabrication and de device characterization of InGaP/GaAs HBTs (heterojunction bipolar transistors) on germanium-on-insulator substrates having comparable device performance to control structures fabricated on GaAs substrates and bulk Ge substrates. In [38] it is reported on the use of GOI substrates (Soitec production, France) for fabrication of epitaxial InP/InAlAs/GaAs/GOI substrates with further production of chips with HBT and HEMT-like devices. Archer et al. [114] used the GOI platform to fabricate GaInP/GaAs doublejunction solar cells. Photovoltaic performance of these devices was comparable to those grown on bulk epi-ready Ge.

As a variant, the donor structure is a system of GeSi layers of different composition (gradient layer up to the pure $\mathrm{Ge}$, including GeSi-based stop layer) grown on the $\mathrm{Si}$ wafer. Smart $\mathrm{Cut}^{\mathrm{TM}}$ technology is also used for donor wafer and GeSi layer exfoliation, and the presence of stop layer makes it easier to obtain the planarity of the film bonded to the handle Si wafer [115]. This technique is positive in the thing that the donor $\mathrm{Ge} / \mathrm{GeSi} / \mathrm{Si}$ structure is grown on the $\mathrm{Si}$ wafer and, hence, it can have a diameter equal to that of the handle wafer. However, as it was mentioned above, Ge films grown this way on $\mathrm{Si}$ wafers have their dislocation density not lower than $10^{6} \mathrm{~cm}^{-2}$ [49].

Fitzgerald and co-workers, having elaborated the Ge-on$\mathrm{Si}$ growth technology through the gradient GeSi layer, fabricated a number of devices on the base of GaAs grown on such a platform $[51,54,57,60]$. However, a $10 \mu \mathrm{m}$ gradient layer did not allow arranging all the elements of integrated circuits based on $\mathrm{Si}$ and GaAs optoelectronics simultaneously on one Si wafer. Understanding this, the authors proposed a new $\mathrm{Si} / \mathrm{Ge} / \mathrm{GeSi} / \mathrm{Si}$-like platform having called it SOLES (Silicon On Lattice-Engineered Substrates) [116, 117]. Using standard Smart Cut ${ }^{\mathrm{TM}}$ technology, they realised the bonding of a $\mathrm{Si}$ thin layer over heterostructure $\mathrm{Ge} / \mathrm{GeSi} / \mathrm{Si}$. Thus, the upper $\mathrm{Si}$ and its under layer $\mathrm{Ge}$ are less than $1 \mu \mathrm{m}$ away in thickness. In the windows out etched in the upper Si layer and oxide, i.e. on the Ge surface, highquality III-V-based heterostructures can be grown, and elements of Complementary Metal Oxide Semiconductor (CMOS) technology can be produced on Si. In [117] the authors demonstrate a working LED's matrix based on heterostructure AlGaInP, grown in the windows of such a platform. They believe that such artificial substrates are one of the ways to realise integrated circuits on silicon with optical connections. 


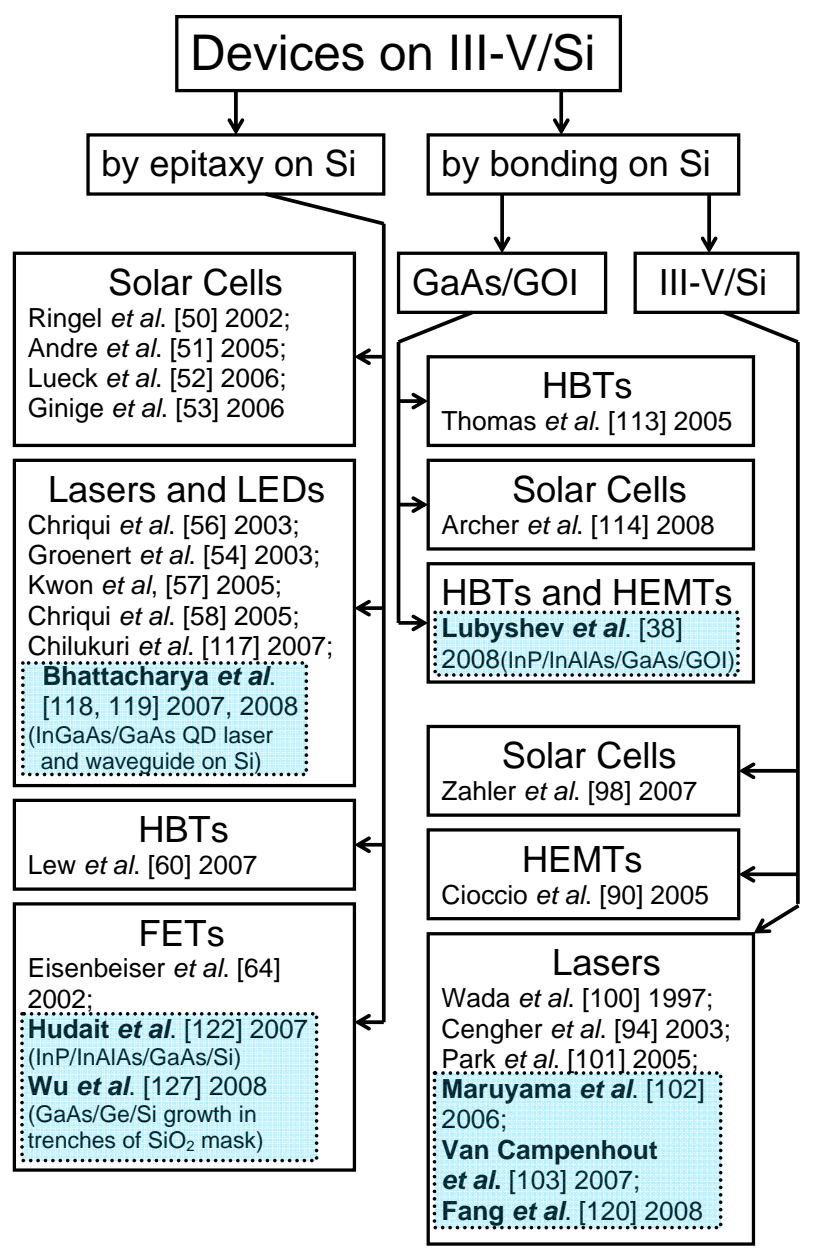

Fig. (8). Publications describing the fabrication of device III-V/Sitype heterostructures and devices on their base grouped according to the character of overcoming lattice parameter misfit between $\mathrm{Si}$ and III-V: epitaxial growth or wafer bonding.

\section{III-V/SI-BASED DEVICES}

Different fabrication ways of device quality GaAs (III-V) on Si wafers are mentioned above, and they can be divided into two trends: purely epitaxial technologies and those whose key element is various methods of bonding crystalline structures with lattices different in their parameters. According to this division, the basic publications in which it is reported on the fabrication of III-V/Si-type device heterostructures and devices on their basis are presented in Fig. (8). As is seen from the figure, the main types of devices fabricated on GaAs wafers are also produced on heterostructures whose basic wafer is Si. Heterojunction bipolar transistors, devices working on minority carriers are especially sensitive to structural imperfections of semiconductor materials. Their successful fabrication can be a test for high quality of the heterostructure used for this purpose. Thus, Lew et al. [60], having grown a GaAs/Ge/GeSi/Si-type heterostructure using purely epitaxial technologies, fabricated HBTs on them. A maximum current gain of $\sim 100$ is reached, which is high enough for microwave applications. The higher leakage current in HBTs on SiGe/Si could be due to the TDs $\left(\sim 10^{6}\right.$ $\mathrm{cm}^{-2}$ ) usually seen in such platforms. At the same time, using

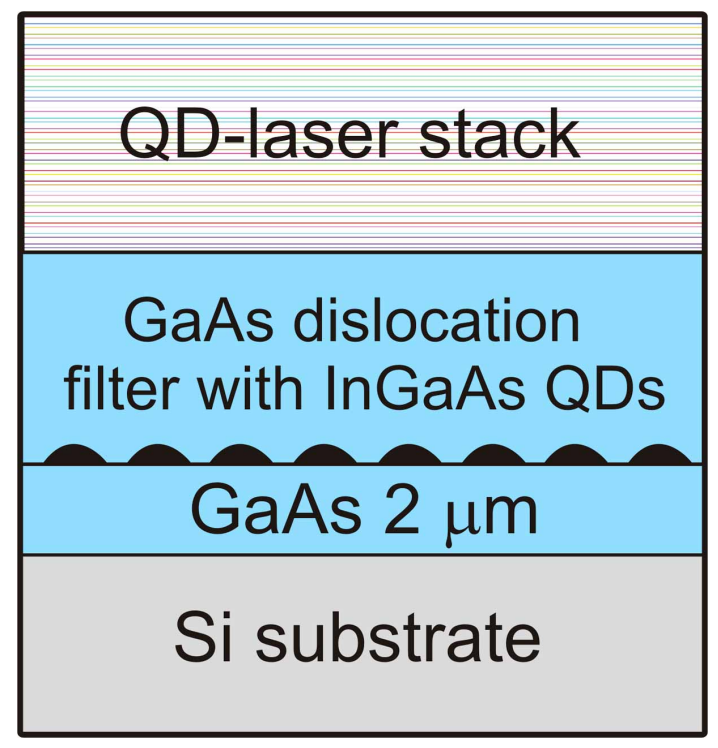

Fig. (9). Scheme of GaAs superlattice-based dislocation filter with InGaAs islands and $\mathrm{In}_{0.5} \mathrm{Ga}_{0.5} \mathrm{As}$ of the quantum-dot laser structure on the Si wafer. By [118].

GOI-based wafers, Lubyshev et al. [38] demonstrated transport properties of III-V HEMTs and large area device characteristics for III-V HBTs on $\mathrm{GeOI} / \mathrm{Si}$ substrates and shown that they were comparable to reference structures grown on InP substrates. The same can be said for lasers: these devices fabricated on the heterostructure bonded to Si have the characteristics close to the standard and even, as it is mentioned in [100], higher output power, due to better thermal conductivity of Si wafer. For lasers fabricated on purely epitaxial $\mathrm{GaAs} / \mathrm{Ge} / \mathrm{GeSi} / \mathrm{Si}$-type heterostructures, the fact of their fabrication proper (as it was mentioned, lasers made on this epitaxial platform were functional not more than 4 hours [55]) is an achievement.

The research papers for the last 2-3 years, in which investigations and elaborations that allowed us to speak about a new developmental era of device technologies based on III-V compounds on Si wafers, are marked in the scheme of Fig. (8) by the dotted rectangles. Yang et al. [118] used the superlattices of "quantum dots" - InGaAs islands on GaAs to improve the GaAs structure grown with MO-CVD directly on the Si wafer (Fig. 9). Such structures were of little difference from GaAs films grown on GaAs wafers in their intensity of upper GaAs layer photoluminiscence. The authors presume that the superlattice with strained $\mathrm{InGaAs}$ (InAs) islands is an effective dislocation filter. $\mathrm{In}_{0.5} \mathrm{Ga}_{0.5} \mathrm{As} /$ GaAs QD separate confinement heterostructure lasers with minimal threshold current $900 \mathrm{~A} / \mathrm{cm}^{2}$ working at room temperature on $1.1 \mu \mathrm{m}$ wavelength were fabricated on such platforms. In their next paper [119], the authors demonstrate monolithic integration of epitaxially grown $\mathrm{InGaAs} / \mathrm{GaAs}$ self-organised quantum dot lasers with hydro-genated amor phous silicon (a:Si-H) waveguides on silicon substrates.

Today's computer processors are strictly electronic devices, transmitting data by means of electrons travelling through copper wires. But this technology is relatively slow and produces heat. Now, researchers have developed optical connection nets that could play a key role in replacing elec- 


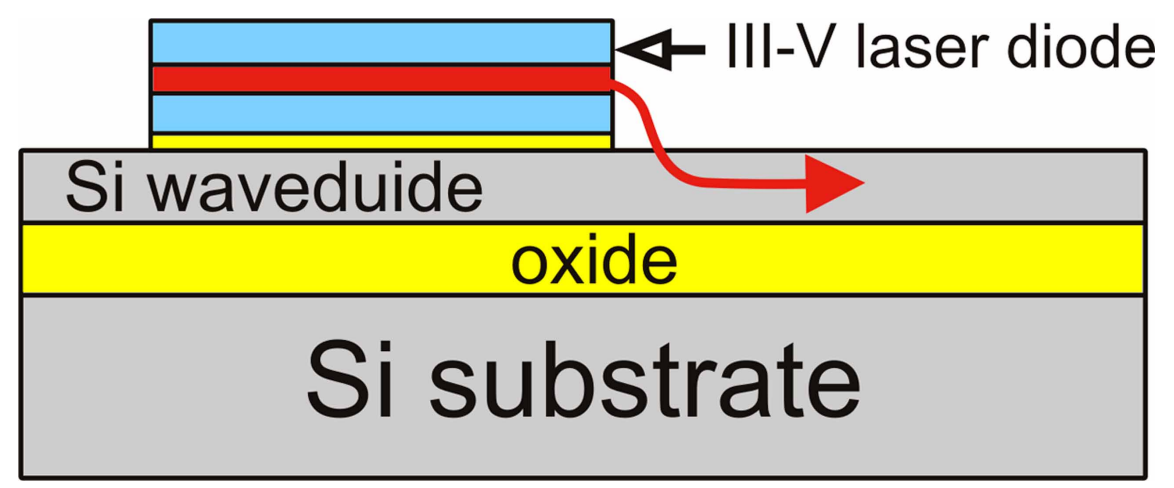

Fig. (10). Scheme of laser diode and Si waveguide assembly on the Si wafer. By [103].

trons and copper wires. Investigations in this direction are scope of activity of Si photonics.

Since Si films on insulator substrate can be used to fabricate compact optical circuits as waveguides, integrations of photonic devices such as lasers, optical amplifiers, electroabsorption modulators, etc. on SOI platforms are very attractive. Integration of laser diodes and silicon waveguides on the Si wafer by bonding is demonstrated in a number of papers $[101-104,120]$. Thus, in [103, 104] the authors demonstrate the electrically injected wave lasing in InP-based microdisk lasers, fabricated through heterogeneous integration of InP on SOI and coupled to a sub-micron silicon wire waveguide. The laser emits at $1.6 \mu \mathrm{m}$, with threshold current as low as $0.5 \mathrm{~mA}$ under continuous-wave operation at room temperature and threshold voltage of $1.65 \mathrm{~V}$.

The scheme of a microdisk laser InP/InAsP-based structure integration with a SOI waveguide circuit is presented in Fig. (10). A microdisk is the part of a thin InP-based layer bonded on top of a SOI wafer. As the authors assert, to fabricate these photonic integrated circuits, standard CMOS technology can be used. An electrically pumped distributed feedback evanescent laser fabricated on the base of InP is proposed for the same purposes in [120]. The III-V epitaxial layers are transferred to the patterned SOI wafer through wafer bonding at $300{ }^{\circ} \mathrm{C}$.

In $[38,121,122]$, new approaches to the creation of device base for III-V compounds on Si wafers, based on solid solutions close to that of InP are demonstrated. As is known HBT- and HEMT-type devices fabricated on the base of InP and on InP wafers are of the fastest operation due to high mobilities of electrons in III-V compounds with band gap width less than $1 \mathrm{eV}$. Maximum oscillation frequency 755 $\mathrm{GHz}$ was achieved [123]. Earlier, successful attempts had been made to replace a more expensive InP wafer by GaAs (see. e.g. [124]). The gradient transfer over GaAs lattice parameter towards InP was realised based on the AlInAs solid solution of variable composition [125]. It turned out that such a buffer layer, $1 \mu \mathrm{m}$ thick only, is sufficient for growing perfect heterostructures and fabrication of efficient HEMTtype devices [126]. Later researchers from IQE Inc. found that such AlInAs-based buffer layer is an effective filter of dislocations if it is grown over GaAs-on-Si wafers. Characteristics of FETs carried out on platform AlInAs/GaAs/Si presented in $[121,122]$ open new prospects for high-speed digital logic applications, and the total buffer AlInAs/GaAs layer thickness, not more than $1.5 \mu \mathrm{m}$ allows us to apply CMOS technologies. Logical is these authors next step in fabrication of fast operation devices on Si wafers, - namely, replacement of epitaxial GaAs/Si structure by GOI platform with further GaAs growth on it, buffer InAlAs layer and then the InP-based junction for HEMT- and HBT-type device fabrication [38]. The authors used GOI substrates by Soitec on which device quality III-V heterostructures were grown, and devices exhibited dc parameters close to reference HBTs were grown on InP substrates.

A new way to largely reduce the TD density in heteroepitaxial films (Ge or GaAs) grown on Si was demonstrated in [127]. Authors used specific selectively growth in trenches of $200 \mathrm{~nm}$ width etched through a thick $\mathrm{SiO}_{2}$ masking layer. Because of the trench aspect ratio (depth/width) was more than 1 , threading dislocations originating at the $\mathrm{Ge} / \mathrm{Si}$ or $\mathrm{GaAs} / \mathrm{Si}$ interfaces terminated at the oxide sidewalls. Fig. (11) shows the sequence of epitaxial growth of $\mathrm{Ge}$ in trenches on Si. Defect trapping was achieved within $200 \mathrm{~nm}$ of the Si surface. After coalescence of Ge crystals and their chemical-mechanical polishing the GaAs film of a high quality could be grown. Depletion-mode $\mathrm{Al}_{2} \mathrm{O}_{3} / \mathrm{GaAs}$ MOSFETs were manufactured on such platform [127].

The point of introduction of GaAs and III-V compounds as elements of silicon CMOS integrated circuits remains unclear. Elaborations of new integrated circuit generations come across the problem of "restriction in size reduction of certain circuit elements with used materials": Si forming the traditional transistor and capacitance, $\mathrm{SiO}_{2}$ and polysilicon, with their size reduction, - reached fundamental physical limits closing to the $100 \mathrm{~nm}$ technological node. The ongoing chip elements decrease requires the introduction of new materials in silicon integrated circuits, necessary to intensify transport properties of transistor channel in CMOS integrated circuits and, respectively, preservation of developmental rate according to Moor's law. On the prognoses formulated in the International Technology Roadmap for Semiconductors (ITRS) 2007 [128], Ge and also III-V compounds could be such materials. The prognosis is based on the fact that the main III-V compounds have a considerably higher electron mobility compared to that of Si. Carries mobility can be increased additionally by strains. 


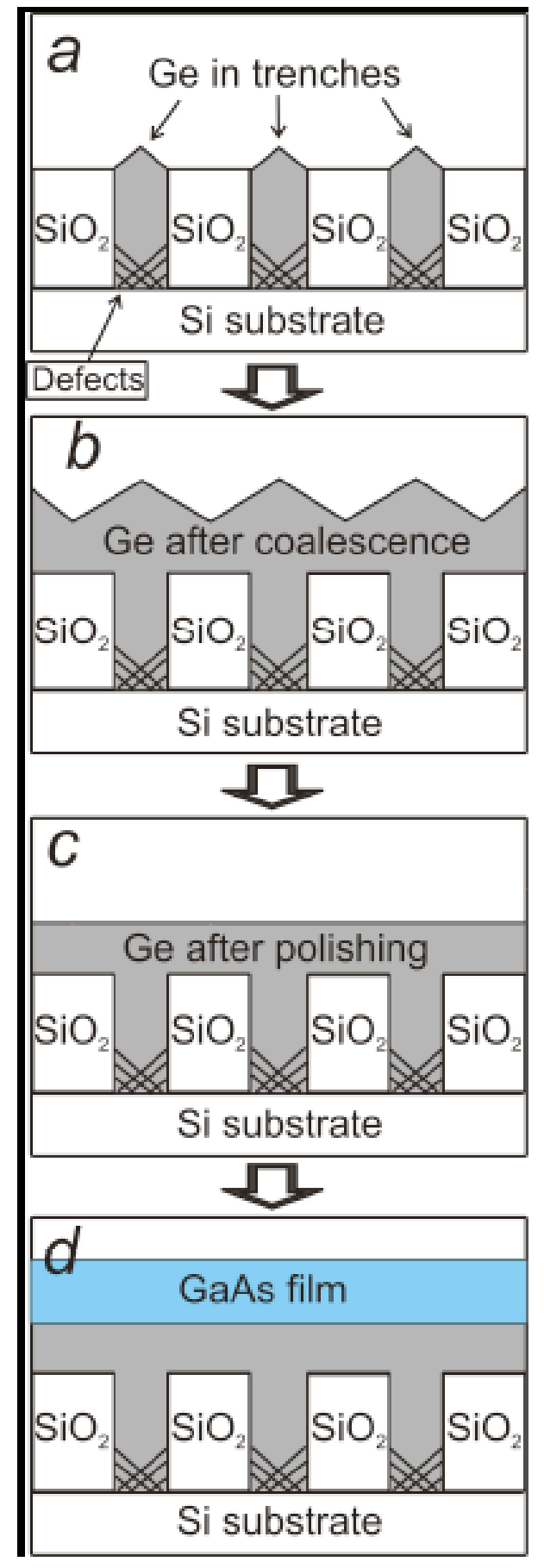

Fig. (11). Cross-sectional schematic view of the GaAs/Ge structure grown on $\mathrm{Si}$. (a) - Ge micro crystals grown in trenches of $\mathrm{SiO}_{2}$ mask; (b) - coalesced Ge film; (c) - Ge film after chemicalmechanical polishing; (d) - GaAs film grown on top of Ge. By [127].

As is indicated in the review by Takagi et al. [129], III-V channel transistors for n-MOSFETs and Ge channel for $\mathrm{p}$ MOSFETs are considered as one of the prospective combinations for fast operation devices. However, despite the vivid profit in the introduction of III-V as a material for the channel with high carrier's mobility, constructive ways of such an introduction are still not clear. The impossibility of epitaxial deposition for ultra-thin, but low defective GaAs films and other compounds on $\mathrm{Si}$ - due to earlier indicated reasons is a considerable, yet not overcome, barrier. The complications are the necessity of different materials for $\mathrm{p}$ - and n-type channels, various most rational channel directions in a crystalline lattice and different strain character (compression tension) for these channels [129-131]. Because of the necessity to fabricate p-MOSFETs with a channel from another material (e.g. Ge) on the same Si wafer, researchers come to the conclusion that III-V compounds will, probably, be selectively introduced onto Si wafers $[132,133]$. Thus, the [133] review authors write: "Due to reduced dimensions.... the extended defect concentration can be reduced as the film dimension in at least two dimensions would be very small. To reiterate, if the conventional Si channel could be replaced by a GaAs channel, the MOSFET operation speed can be improved greatly". However, even in channel size reduction down to several tens of nanometers, GaAs nucleation in its epitaxial growth on $\mathrm{Si}$ will proceed as it was shown earlier, namely as separate islands. According to Asai et al. [15], $\sim 10$ islands on the area $100 \times 100 \mathrm{~nm}^{2}$ form at the earliest film growth stage. Just before their coalescence, islands become dislocated. So far there are no grounds to presume the thing that the island character of GaAs-on-Si initial part of growth will be overcome with dislocation density reduction down to not more than $10^{6} \mathrm{~cm}^{-2}$ in a completely relaxed GaAs film. It is significant to note that the linear density of edge misfit dislocations which are necessary to compensate the lattice parameter difference between GaAs and $\mathrm{Si}$, is $\sim 100 / \mu \mathrm{m}$ and they inevitably are in the GaAs/Si interface and close to it. Contrary to epitaxial growth the way of GaAs bonding with $\mathrm{Si}$ wafers is virtually free of that kind of defects.

\section{SUMMARY}

For the last more than 20 years researchers have been trying to integrate $\mathrm{Si}$ - and III-V-based devices on the most efficient silicon wafer. Two ways of overcoming the main barrier in the successful integration of III-V-based devices on $\mathrm{Si}$ wafers with a 4\%- and more lattice parameter difference between them have outlined for the last several years. It is a purely epitaxial growth using gradient buffer layers and different dislocation density reduction techniques: annealing, dislocation "filters", special regimes of GaAs-on-Si initial growth steps. Another way - bonding III-V compounds and III-V-based heterostructures on silicon wafers or using GOI (germanium-on-silicon-insulator) substrates - becomes more popular in connection with the development of various nonepitaxial integration methods for two heterogeneous semiconductor materials.

The main advantage of epitaxial growth consists in that the Si wafer is the only one used in this technology. However, because of a high lattice parameters difference III-V and $\mathrm{Si}$, it is possibly to grow relatively perfect GaAs (and other III-V) films with dislocation density not lower than $10^{6} \mathrm{~cm}^{-2}$, which is insufficient for long operation of certain type devices (lasers, photodiodes). Big distance in thickness between GaAs and Si surfaces exceeding $10 \mu \mathrm{m}$, in case of using gradient baffer $\mathrm{Ge} / \mathrm{GeSi} / \mathrm{Si}$ layers, is a considerable barrier for high resolution lithography methods for connections between $\mathrm{Si}$ and III-V neighbours on the substrate. 
Non-epitaxial bonding methods give a new degree of freedom and enable us to make new combinations of materials that could not be realised earlier by epitaxial growth. Thus, a big number of defects, inevitably appearing in the film under heteroepitaxy, is absent under the transfer by bonding. Herein, it turns out possible to fabricate such structures, in which GaAs (also other III-V compounds) and $\mathrm{Si}$ are directly close to each other, and this is one of the key factors for integration of silicon integrated circuits and GaAs optoelectronics on one silicon wafer.

The results achieved in device application of III-V-on-Si can be characterised in a different way depending on the earlier set aims:

-Replacement of GaAs and InP wafers for Si to fabricate III-V-based semiconductor devices on a cheaper, biggersized, bigger strength and higher thermal conductivity $\mathrm{Si}$ wafer. Several solutions were proposed: high temperature anneals and TCA of epitaxially grown $\mathrm{GaAs} / \mathrm{Si}$ heterostructures, epitaxial transition from Si through buffer GeSi layers to Ge (and then GaAs growth), using buffer AlInAs layers to InP-related heterostructures, involving a new GOI wafer or $\mathrm{GaAs} / \mathrm{Si}$ and InP/Si wafers fabricated by wafer bonding. IIIV-based devices: lasers, solar cells, HBTs, HEMTs and QWFETs are fabricated on such artificial wafers.

-Integration of devices based on III-V compounds and silicon planar technology on the Si wafer. Examples for the beginning of such integration - InP-based lasers and silicon waveguides, AlGaInP-based photodiode matrix arrays and contacts to them, realised using CMOS technology - were demonstrated.

-Acceleration of CMOS integrated circuits fast operation through the replacement of $\mathrm{Si}$ channels in FETs by those with higher electron mobility based on GaAs (InGaAs). Despite the vivid profit in the introduction of III-V compounds as a material for a channel with high mobility of electrons, constructive ways of such an introduction are still not clear.

\section{REFERENCES}

[1] Wang, W.I. Molecular beam epitaxial growth and material properties of GaAs and AlGaAs on Si (100). Appl. Phys. Lett., 1984, 44, 1149.

[2] Fischer, R.; Masselink, W.T.; Klem, J.; Henderson, T.; McGlinn, T.C.; Klein, M.V.; Morkoc, H.; Mazur, J.H.; Washburn, J. Growth and properties of GaAs/AlGaAs on nonpolar substrates using molecular beam epitaxy. J. Appl. Phys., 1985, 58, 374.

[3] Masselink, W.T.; Henderson, T.; Klem, J.; Fischer, R.; Pearah, P.; Morkoc, H.; Hafich, M.; Wang, P.D.; Robinson, G.Y. Optical properties of GaAs on (100)Si using molecular beam epitaxy. Appl. Phys. Lett., 1984, 45, 1309.

[4] Tsaur, B-Y.; Metze, G.M. Molecular beam epitaxy of GaAs and AlGaAs on Si. Appl. Phys. Lett., 1984, 45, 535.

[5] Uppal, P.N.; Kroemer, H. Molecular beam epitaxial growth of GaAs on Si(211). J. Appl. Phys., 1985, 58, 2195.

[6] kiyama, M.; Kawarada, Y.; Kaminishi K. Growth of single domain GaAs layer on (100)-oriented Si substrate by MOCVD. Jpn. J. Appl. Phys., 1984, 23, L843.

[7] Fischer, R.J.; Chand, N.; Kopp, W.; Morkoc, H.; Erickson, L.P.; Youngman, R. GaAs bipolar transistors grown on (100) $\mathrm{Si}$ substrates by molecular beam epitaxy. Appl. Phys. Lett., 1985, 47, 397.

[8] Soga, T.; Hattori, S.; Sakai, S.; Takeyasu, M.; Umeno, M. Characterization of epitaxially grown GaAs on Si substrates with III-V compounds intermediate layers by metalorganic chemical vapour deposition. J. Appl. Phys., 1985, 57, 4578.
[9] Fischer, R.; Morkoc, H.; Neumann, D.A.; Zabel, H.; Choi, C.; Otsuka, N.; Longerbone, M.; Erickson, L.P. Material properties of high-quality GaAs epitaxial layers grown on Si substrates. J. Appl. Phys., 1986, 60, 1640.

[10] Lee, J.W.; Shichijo, H.; Tsai, H.L.; Matyi, R.J. Defect reduction by thermal annealing of GaAs layers grown by molecular beam epitaxy on Si substrates. Appl. Phys. Lett,. 1987, 50, 31.

[11] Yamaguchi, M.; Nishioka, T.; Sugo, M. Analysis of strained-layer superlattice effects on dislocation density reduction in GaAs on $\mathrm{Si}$ substrates. Appl. Phys. Lett., 1989, 54, 24.

[12] Yamaguchi, M.; Sugo, M.; Itoh, Y. Misfit stress dependence of dislocation density reduction in GaAs films on Si substrates grown by strained-layer superlattices. Appl. Phys. Lett., 1989, 54, 2568.

[13] Yamaguchi, M. Dislocation density reduction in heteroepitaxial III$\mathrm{V}$ compound films on Si substrates for optical-devices. J. Mater. Res., 1991, 6, 376.

[14] Fang, S.F.; Adomi, S.; Iyer, S.; Morkoc, H.; Zabel, H.; Choi, C.; Otsuka, N. Gallium arsenide and other compound semiconductors on silicon. J. Appl. Phys., 1990, 68, R31.

[15] Asai, K.; Kamei, K.; Katahama, H. Lattice relaxation of GaAs islands grown on $\mathrm{Si}(100)$ substrate. Appl. Phys. Lett., 1997, 71, 701.

[16] Tsai, H.L.; Kao, Y.C. Generation and propagation of threading dislocations in GaAs grown on Si. J. Appl. Phys., 1990, 67, 2862.

[17] Usui, H.; Yasuda, H.; Mori, H. Morphology and lattice coherency in GaAs nanocrystals grown on $\mathrm{Si}(100)$ surface. Appl. Phys. Lett., 2006, 89, 173127.

[18] Vinokurov, D.A.; Lantratov, V.M.; Sinitsyn, M.A.; Ulin, V. P.; Faleev, N.N.; Fedorova, O.M.; Shaiovich, Y.L.; Yavich, B.S. Properties and special features of crystallization of epitaxial GaAs films grown on $\mathrm{Si}(100)$ substrates by the method of 2-stage deposition using the MOCVD hydride process. Sov. Phys. Semicond., 1991, 25, 617.

[19] Joshkin, V.; Orlikovsky, A.; Oktyabrsky, S.; Dovidenko, K.; Kvit, A.; Muhamedzanov, I.; Pashaev, E. Biaxial compression in GaAs thin-films grown on Si. J. Cryst. Growth, 1995, 147, 13.

[20] Tachikawa, M.; Mori, H.; Sugo, M.; Itoh, Y. Continuous GaAs film growth on epitaxial $\mathrm{Si}$ surface in initial-stage of $\mathrm{GaAs} / \mathrm{Si}$ heteroepitaxy. Jap. J. Appl. Phys., 1993, 32, L1252.

[21] Hao, M.S.; Liang, J.W.; Zheng, L.X.; Deng, L.S.; Xiao, Z.B.; Hu, $\mathrm{X}$.W. Photoluminescence spectrum study of the GaAs/Si epilayer grown by using a thin amorphous Si film as buffer layer. Jpn. J. Appl. Phys., 1995, 34, L900.

[22] Taylor, P.J.; Jesser, W.A.; Benson, J.D.; Martinka, P.M.; Dinan, J.H.; Bradshaw, J.; Lara-Taysing, M.; Leavitt, R.P.; Simonis, G.; Chang, W.; Clark III, W.W.; Bertness, K.A. Optoelectronic device performance on reduced threading dislocation density $\mathrm{GaAs} / \mathrm{Si}$. $J$. Appl. Phys., 2001, 89, 4365.

[23] Akahori, K.; Wang, G.; Okumura, K.; Soga, T.; Jimbo, T.; Umeno, M. Improvement of the MOCVD-grown InGaP-on-Si towards high-effciency solar cell application. Solar Energy Mater. Solar Cells, 2001, 66, 593.

[24] Uen, W.Y.; Li, Z-Y.; Huang, Y-C.; Chen, M-C.; Yang, T-N.; Lan, S-M.; Wu, C-H.; Hong, H-F.; Chi, G-C. Heteroepitaxial growth of GaAs on Si by MOVPE using a-GaAs/a-Si double-buffer layers. $J$. Cryst. Growth, 2006, 295, 103.

[25] Ma, K.; Urata, R.; Miller, D.A.B.; Harris, J.S. Low-temperature growth of GaAs on Si used for ultrafast photoconductive switches. IEEE J. Quantum Electron., 2004, 40, 800.

[26] Ackaert, A.; Demeester, P.; Buydens, L.; Coudenus, G.; Vandaele, P.; Renaud, M. Selective MOVPE growth of GaAs on Si and its applications to LEDs. J. Cryst. Growth, 1991, 107, 822.

[27] Chand, N.; Ren, F.; Macrander, A.T.; van der Ziel, J.P.; Sergent, A.M.; Hull, R.; Chu, S.N.G.; Chen, Y.K.; Lang, D.V. GaAs-on-Si improved growth-conditions, properties of undoped GaAs high mobility, and fabrication of high-performance AlGaAs GaAs selectively doped heterostructure transistors and ring oscillators. $J$. Appl. Phys., 1990, 67, 2343.

[28] Mori, H.; Tachikawa, M.; Sugo, M.; Itoh, Y. GaAs heteroepitaxy on an epitaxial $\mathrm{Si}$ surface with a low-temperature process. Appl. Phys. Lett., 1993, 63, 1963.

[29] Yodo, T.; Tamura, M. GaAs heteroepitaxial growth on $\mathrm{Si}$ substrates with thin $\mathrm{Si}$ interlayers in situ annealed at high temperatures. J. Vac. Sci. Technol. B, 1995, 13, 1000.

[30] Uen, W.Y.; Ohori, T.; Nishinaga, T. Molecular beam epitaxy of GaAs on $0.3^{\circ}$-misoriented epitaxial Si substrates. J. Cryst. Growth, 
1995, 156, 133.

[31] Takano, Y.; Hisaka, M.; Fujii, N.; Suzuki, K.; Kuwahara, K.; Fuke, S. Reduction of threading dislocations by InGaAs interlayer in GaAs layers grown on Si substrates. Appl. Phys. Lett., 1998, 73, 2917.

[32] Kakinuma, H.; Ueda, T.; Gotoh, S.; Yamagishi, C. Reduction of threading dislocations in $\mathrm{GaAs}$ on $\mathrm{Si}$ by the use of intermediate GaAs buffer layers prepared under high V-III ratios. J. Cryst. Growth, 1999, 205, 25.

[33] Li, J.Z.; Bai, J.; Major, C.; Carroll, M.; Lochtefeld, A.; Shellenbarger, Z. Defect reduction of GaAs/Si epitaxy by aspect ratio trapping. J. Appl. Phys., 2008, 103, 106102.

[34] Luo, G-L.; Hsieh, Y-C.; Chang, E.Y.; Pilkuhn, M.H.; Chien, C-H.; Yang, T-H.; Cheng, C-C.; Chang, C-Y. High-speed GaAs metal gate semiconductor field effect transistor structure grown on a composite Ge/GexSi1-x /Si substrate. J. Appl. Phys., 2007, 101, 084501 .

[35] Tanoto, H.; Yoon, S.F.; Loke, W.K.; Chen, K.P.; Fitzgerald, E.A.; Dohrman, C.; Narayanan, B. Heteroepitaxial growth of GaAs on (100) Ge/Si using migration enhanced epitaxy. J. Appl. Phys., 2008, 103, 104901 .

[36] Arokiaraj, J.; Soga, T.; Jimbo, T.; Umeno, M. High-quality GaAs on Si substrate by the epitaxial lift-off technique using $\mathrm{SeS}_{2}$. Appl. Phys. Lett., 1999, 75, 3826.

[37] Scholz, S.; Bauer, J.; Leibiger, G.; Herrnberger, H.; Hirsch, D.; Gottschalch, V. MOVPE growth of GaAs on Ge substrates by inserting a thin low temperature buffer layer. Cryst. Res. Technol., 2006, 41, 111 .

[38] Lubyshev, D.; Fastenau, J.M.; Wu, Y.; Liu, W.K.; Bulsara, M.T.; Fitzgerald, E.A.; Hoke, W.E. Molecular beam epitaxy growth of metamorphic high electron mobility transistors and metamorphic heterojunction bipolar transistors on $\mathrm{Ge}$ and Ge-on-insulator/Si substrates. J. Vac. Sci. Technol. B, 2008, 26, 1115.

[39] Neave, J.H.; Larsen, P.K.; Joyce, E.A.; Gowers, J.P.; van der Veen, J.F. Some observations on Ge:GaAs(001) and GaAs:Ge(001) interfaces and films. J. Vac. Sci. Technol. B, 1983, 1, 668.

[40] Cho, N-H.; De Cooman, B.C.; Carter, C.B.; Fletcher, R.; Wagner, K. Antiphase boundaries in GaAs. Appl. Phys. Lett., 1985, 47, 879.

[41] Mizuguchi, K.; Hayafuji, N.; Ochi, S.; Murotani, T.; Fujikawa, K. MOCVD GaAs growth on Ge (100) and Si (100) substrates. J. Cryst. Growth, 1986,77, 509.

[42] Strite, S.; Ünlü, M.S.; Adomi, K.; Gao, G-B.; Agarwal, A.; Rockett, A.; Morkoc, H. GaAs/Ge/GaAs heterostructures by molecular beam epitaxy. J. Vac. Sci. Technol. B, 1990, 8, 1131.

[43] Fitzgerald, E.A.; Xie, Y.H.; Green, M.L.; Brasen, D.; Kortan, A.R.; Michel, J.; Mii, Y-J.; Weir, B.E. Totally relaxed GexSil-x layers with low threading dislocation densities grown on $\mathrm{Si}$ substrates. Appl. Phys. Lett., 1991, 59, 811.

[44] Samavedam, S.B.; Fitzgerald, E.A. Novel dislocation structure and surface morphology effects in relaxed $\mathrm{Ge} / \mathrm{Si}-\mathrm{Ge}$ (graded)/Si structures. J. Appl. Phys., 1997, 81, 3108.

[45] Currie, M.T.; Samavedam, S.B.; Langdo, T.A.; Leitz, C.W.; Fitzgerald, E.A. Controlling threading dislocation densities in Ge on Si using graded SiGe layers and chemical-mechanical polishing. Appl. Phys. Lett., 1998, 72, 1718.

[46] Samavedam, S.B.; Currie, M.T.; Langdo, T.A.; Fitzgerald, E.A. High-quality germanium photodiodes integrated on silicon substrates using optimized relaxed graded buffers. Appl. Phys. Lett., 1998, 73, 2125.

[47] Lee, M.L.; Fitzgerald, E.A.; Bulsara, M.T.; Currie, M.T.; Lochtefeld, A. Strained $\mathrm{Si}, \mathrm{SiGe}$, and $\mathrm{Ge}$ channels for highmobility metal-oxide-semiconductor field-effect transistors. $J$. Appl. Phys., 2005, 97, 011101.

[48] Sieg, R.M.; Ringel, S.A.; Ting, S.M.; Samavedam, S.B.; Currie, M.; Langdo, T.; Fitzgerald, E. A. Toward device-quality GaAs growth by molecular beam epitaxy on offcut $\mathrm{Ge} / \mathrm{Si1}-\mathrm{xGex} / \mathrm{Si}$ substrates. J. Vac. Sci. Technol. B, 1998, 16, 1471.

[49] Carlin, J.A.; Ringel, S.A.; Fitzgerald, E.A.; Bulsara, M. Highlifetime GaAs on Si using GeSi buffers and its potential for space photovoltaics. Solar Energy Mater. Solar Cells, 2001, 66, 621.

[50] Ringel, S.A.; Carlin, J.A.; Andre, C.L.; Hudait, M.K.; Gonzalez, M.; Wilt, D.M.; Clark, E.B.; Jenkins, P.; Scheiman, D.; Allerman, A.; Fitzgerald, E.A.; Leitz, C.W. Single-junction InGaP/GaAs solar cells grown on $\mathrm{Si}$ substrates with $\mathrm{SiGe}$ buffer layers. Prog. Photovolt., 2002, 10, 417.

[51] Andre, C.L.; Carlin, J.A.; Boeckl, J.J.; Wilt, D.M.; Smith, M.A.;
Pitera, A.J; Lee, M.L.; Fitzgerald, E.A.; Ringel, S.A. Investigations of high-performance GaAs solar cells grown on $\mathrm{Ge}_{-} \mathrm{Si}_{1-\mathrm{x}} \mathrm{Ge}_{\mathrm{x}}-\mathrm{Si}$ substrates. IEEE Trans. Electron Devices, 2005, 52, 1055.

[52] Lueck, M.R.; Andre, C.L.; Pitera, A.J.; Lee, M.L.; Fitzgerald, E.A.; Ringel, S.A. Dual junction GaInP/GaAs solar cells grown on metamorphic $\mathrm{SiGe} / \mathrm{Si}$ substrates with high open circuit voltage. IEEE Electron Devices Lett., 2006, 27, 142.

[53] Ginige, R.; Corbett, B.; Modreanu, M.; Barrett, C.; Hilgarth, J.; Isella, G.; Chrastina, D.; von Kaenel, H. Characterization of Ge-on$\mathrm{Si}$ virtual substrates and single junction GaAs solar cells. Semicond. Sci. Technol., 2006, 21, 775.

[54] Groenert, M.E.; Leitz, C.W.; Pitera, A.J.; Yang, V. Monolithic integration of room-temperature $\mathrm{cw}$ GaAs/AlGaAs lasers on $\mathrm{Si}$ substrates via relaxed graded GeSi buffer layers. J. Appl. Phys., 2003, 93, 362.

[55] Groenert, M.E.; Pitera, A.J.; Ram, R.J.; Fitzgerald, E.A. Improved room-temperature continuous wave GaAs/AlGaAs and InGaAs/GaAs/AlGaAs lasers fabricated on $\mathrm{Si}$ substrates via relaxed graded GexSi1-x buffer layers. J. Vac. Sci. Technol., B 2003, 21, 1064.

[56] Chriqui, Y.; Saint-Girons, G.; Bouchoule, S.; Moison, J-M.; Isella, G.; von Kaenel, H.; Sagnes I. Room temperature laser operation of strained InGaAs/GaAs QW structure monolithically grown by MOVCD on LE-PECVD Ge/Si virtual substrate. Electron. Lett., 2003, 39, 1658.

[57] Kwon, O.; Boeckl, J.; Lee, M.L.; Pitera, A.J.; Fitzgerald, E.A.; Ringel, S.A. Growth and properties of AlGaInP resonant cavity light emitting diodes on $\mathrm{Ge} / \mathrm{SiGe} / \mathrm{Si}$ substrates. J. Appl. Phys., 2005, 97, 034504.

[58] Chriqui, Y.; Saint-Girons, G.; Isella, G.; von Kaenel, H.; Bouchoule, S.; Sagnes, I. Long wavelength room temperature laser operation of a strained InGaAs/GaAs quantum well structure monolithically grown by metalorganic chemical vapour deposition on a low energy-plasma enhanced chemical vapour deposition graded misoriented Ge/Si virtual substrate. Opt. Mater., 2005, 27, 46.

[59] Yang, V.K.; Groenert, M.E.; Taraschi, G.; Leitz, C.W.; Pitera, A.J.; Currie, M.T.; Cheng, Z.; Fitzgerald, E.A. Monolithic integration of III-V optical interconnects on $\mathrm{Si}$ using SiGe virtual substrates. $J$. Mater. Sci. Mater. Electron., 2002, 13, 377.

[60] Lew, K.L.; Yoon, S.F.; Loke, W.K.; Tanoto, H.; Dohrman, C.L.; Isaacson, D.M.; Fitzgerald, E.A. High gain AlGaAs/GaAs heterojunction bipolar transistor fabricated on $\mathrm{SiGe} / \mathrm{Si}$ substrate. $J$. Vac. Sci. Technol., B, 2007, 25, 902.

[61] Motorola and IQE grow GaAs on large-area Si substrates. Comp. Semiconductor, 2001, 7(9), 47.

[62] Yu, Z.; Ramdani, J.; Curless, J.; Overgaard, C.; Finder, J.; Droopad, R.; Eisenbeiser, K.; Hallmark, J.; Ooms, W.; Kaushik, V. Epitaxial oxide thin films on Si(001). J. Vac. Sci. Technol., B, 2000, 18, 2139.

[63] Yu, Z.; Droopad, R.; Jordan, D.; Curless, J.; Liang, Y.; Overgaard, C.; Li, H.; Talin, A.; Eschrich, T.; Craigo, B.; Eisenbeiser, K.; Emrick, R.; Finder, J.; Hu, X.; Wei, Y.; Edwards, J.; Convey, D.; Moore, K.; Marshall, D.; Ramdani, J.; Tisinger, L.; Ooms, W.; O'Steen, M.; Towner, F.; Hierl, T. GaAs-Based Heterostructures on silicon in GaAs. In Mantech Conference, San Diego, California, April 8-11, 2002.

[64] Eisenbeiser, K.; Emrick, R.; Droopad, R.; Yu, Z.; Finder, J.; Rockwell, S.; Holmes, J.; Overgaard, C.; Ooms, W. GaAs MESFETs fabricated on $\mathrm{Si}$ substrates using a $\mathrm{SrTiO}_{3}$ buffer layer. IEEE Electron Device Lett., 2002, 23, 300.

[65] Dropad, R.; Yu, Z.; Li, H.; Liang, Y.; Overgaard, C.; Demkov, A.; Zhang, X.; Moore, K.; Eisenbeiser, K.; Hu, M.; Curless, J.; Finder, J. Development of integrated heterostructures on silicon by MBE. J. Cryst. Growth, 2003, 251, 638.

[66] Chediak, A.; Scott, K.; Zhang, P. Interaction of GaAs/Si with buffer layers and its impact on device integration. TICS 4, Prof. Sands, MSE, 2002, 225, 1.

[67] Datta, S.; Dewey, G.; Fastenau, JM.; Hudait, M.K.; Loubychev, D.; Liu, W.K.; Radosavljevic, M.; Rachmady, W.; Chau, R. Ultrahighspeed $0.5 \mathrm{~V}$ supply voltage $\operatorname{In}_{0.7} \mathrm{Ga}_{0.3} \mathrm{As}$ quantum-well transistors on silicon substrate. IEEE Electron Device Lett., 2007, $28,685$.

[68] Tsuji, T.; Yonezu, H.; Ohshima, N. Selective epitaxial growth of $\mathrm{GaAs}$ on $\mathrm{Si}$ with strained short-period superlattices by molecular beam epitaxy under atomic hydrogen irradiation. J. Vac. Sci. Technol., B, 2004, 22, 1428. 
[69] Geisz, J.F.; Olson, J.M.; Romero, M.J.; Jiang, C.S.; Norman, A.G. Lattice-mismatched GaAsP Solar Cells Grown on Silicon by $O M V P E$. In 4th world conference on photovoltaic energy conversion, Waikoloa, Hawaii, May 7-12, 2006.

[70] Yu, X.; Kuo, P.S.; Ma, K.; Levi, O.; Fejer, M.M.; Harris, J.S. Single-phase growth studies of $\mathrm{GaP}$ on $\mathrm{Si}$ by solid-source molecular beam epitaxy. J. Vac. Sci. Technol. B, 2004, 22, 1451.

[71] Putuato, M.A.; Bolkhovityanov, Yu.B.; Vasilenko, A.P.; Gutakovskii, A.K. Crystal quality of GaP films grown by solid source $\mathrm{MBE}$ on $\mathrm{Si}$ with atomic hydrogen irradiation semiconductors, 2009, 43(9), 1235.

[72] Matthews, J.W.; Blakeslee, A.E. Defects in epitaxial multilayers. J. Cryst. Growth, 1974, 27, 118.

[73] Sadeghi, M.; Wang, S. Growth of GaP on Si substrates by solidsource molecular beam epitaxy. J. Cryst. Growth, 2001, 227/228, 279.

[74] Komatsu, Y.; Hosotani, K.; Fuyuki, T.; Matsunami, H. Heteroepitaxial growth of $\mathrm{InGaP}$ on $\mathrm{Si}$ with $\mathrm{InGaP} / \mathrm{GaP}$ stepgraded buffer layers. Jpn. J. Appl. Phys., 1997, 36, 5425.

[75] Wright, S.L.; Kroemer, H.; Inada, M. Molecular beam epitaxial growth of GaP on Si. J. Appl. Phys., 1984, 55, 2916.

[76] Mori, H.; Ogasawara, M.; Yamamoto, M.; Tachikawa, M. New hydride vapour phase epitaxy for GaP growth on Si. Appl. Phys. Lett., 1987, 51, 1245.

[77] Suzuki, T.; Mori, M.; Jiang, Z K.; Soga, T.; Jimbo, T.; Umeno, M. Tilt deformation of metalorganic chemical vapor-deposition grown GaP on Si substrate. Jpn. J. Appl. Phys., 1992, 31, 2079.

[78] Bi, W.G.; Mei, X.B.; Tu, C.W. Growth studies of GaP on Si by gas-source molecular beam epitaxy. J. Cryst. Growth, 1996, 164, 256.

[79] Takagi, Y.; Yonezu, H.; Samonji, K.; Tsuji, T.; Ohshima, N. Generation and suppression process of crystalline defects in $\mathrm{GaP}$ layers grown on misoriented $\operatorname{Si}\left(\begin{array}{lll}1 & 0 & 0\end{array}\right)$ substrates. J. Cryst. Growth, 1998, 187, 42 .

[80] Dixit, V.K.; Ganguli, T.; Sharma, T.K.; Kumar, R.; Porwal, S.; Shukla, V.; Ingale, A.; Tiwari, P.; Nath, A.K. Studies on MOVPE growth of GaP epitaxial layer on $\operatorname{Si}\left(\begin{array}{lll}0 & 0 & 1\end{array}\right)$ substrate and effects of annealing. J. Cryst. Growth, 2006, 293, 5.

[81] Soga, T.; Jimbo, T.; Umeno, M. Dislocation generation mechanisms for $\mathrm{GaP}$ on $\mathrm{Si}$ grown by metalorganic chemical vapor deposition. Appl. Phys. Lett., 1993, 63, 2543.

[82] Kunert, B.; Nemeth, I.; Volz, K.; Stolz, W. Heteroepitaxy of GaP on Si Substrate for the Monolithic Integration of the novel III/V Laser Material Ga(NAsP)/GaP on Si. In Int. Conf. Silicon Epitaxy and Heterostructures (ICSI-5), Marseille, France, May, 2007, p.178.

[83] Tsuji, T.; Yonezu, H.; Yokozeki, M.; Takagi, Y.; Fujimoto, Y.; Ohshima, N. Defect-controlled selective epitaxial growth of GaP on $\mathrm{Si}$ by migration-enhanced epitaxy under atomic hydrogen irradiation. Jpn. J. Appl. Phys., 1997, 36, 5431.

[84] Gösele, U.; Bluhm, Y.; Kästner, G.; Kopperschmidt, P.; Kräuter, G.; Scholz, R.; Schumacher, A.; Senz, St.; Tong, Q-Y; Huang, L-J.; Chao, Y-L.; Lee, T.H. Fundamental issues in wafer bonding. $J$. Vac. Sci. Technol., A, 1999, 17, 1145.

[85] Tong Q.Y.; Cha G.H.; Gafiteanu R.; Gösele U. Low-temperature wafer direct bonding. J. Microelectromech. Syst., 1994, 3, 29.

[86] Takagi, H.; Maeda, R. Direct bonding of two crystal substrates at room temperature by Ar-beam surface activation. J. Cryst. Growth, 2006, 292, 429.

[87] McKay, K.S.; Lu, F.P.; Kim, J.; Yi, C.; Brown, A.S.; Hawkins, A.R. Band discontinuity measurements of the wafer bonded InGaAs/Si heterojunction. Appl. Phys. Lett., 2007, 90, 222111.

[88] Antypas, G.A.; Edgecumbe, J. Glass-sealed GaAs-AlGaAs transmission photocathode. Appl. Phys. Lett., 1975, 26, 371.

[89] Fleming J.G.; Roherty-Osmun E.; Godshall N.A. Low-temperature, high-strength, wafer-to-wafer bonding. J. Electrochem. Soc., 1992, 139, 3300.

[90] Cioccio, L.D.; Jalaguier, E.; Letertre, F. III-V layer transfer onto silicon and applications. Phys. Status Solidi, A, 2005, 202, 509.

[91] Peterson, R.L.; Hobart, K.D.; Kub, F.J.; Yin, H.; Sturm, J.C. Reduced buckling in one dimension versus two dimensions of a compressively strained film on a compliant substrate. Appl. Phys. Lett., 2006, 88, 201913.

[92] Huang, H.; Ren, X.; Wang, W.; Song, H.; Wang, Q.; Cai, S.; Huang, Y. Low temperature InP/Si wafer bonding using boride treated surface. Appl. Phys. Lett., 2007, 90, 161102.
[93] Lin, H.C.; Chang, K.L.; Pickrell, G.W.; Hsieh, K.C.; Cheng, K.Y. Low temperature wafer bonding by spin on glass. J. Vac. Sci. Technol. B, 2002, 20, 752.

[94] Cengher, D.; Hatzopoulos, Z.; Gallis, S.; Deligeorgis, G.; Aperathitis, E.; Androulidaki, M.; Alexe, M.; Dragoi, V.; KyriakisBitzaros, E.D.; Halkias, G.; Georgakilas, A. Fabrication of GaAs laser diodes on Si using low-temperature bonding of MBE-grown GaAs wafers with Si wafers. J. Cryst. Growth, 2003, 251, 754.

[95] Gösele, U.; Tong, Q-Y. Semiconductor wafer bonding. Annu. Rev. Mater. Sci., 1998, 28, 215.

[96] Bruel, M. Silicon-on-Inasulator material technology. Electron. Lett., 1995, 31, 1201.

[97] Hayashi, S.; Bruno, D.; Goorsky, M.S. Temperature dependence of hydrogen-induced exfoliation of InP. Appl. Phys. Lett., 2004, 85, 236.

[98] Zahler, J.M.; Tanabe, K.; Ladous, C.; Pinnington, T.; Newman, F.D.; Atwater, H.A. High efficiency InGaAs solar cells on Si by InP layer transfer. Appl. Phys. Lett., 2007, 91, 012108.

[99] Chen, P.; Jing, Y.; Lau, S.S.; Xu, D.; Mawst, L.; Alford, T.L.; Paulson, C.; Kuech, T.F. High crystalline-quality III-V layer transfer onto Si substrate. Appl. Phys. Lett., 2008, 92, 092107.

[100] Wada, H.; Kamijoh, T. 1.3- mm InP-InGaAsP lasers fabricated on Si substrates by wafer bonding. IEEE J. Selected Top. Quantum Electron., 1997, 3, 937.

[101] Park, H.; Fang, A.W.; Kodama, S.; Bowers, J.E. Hybrid silicon evanescent laser fabricated with silicon waveguide and III-V offset quantum wells. Opt. Express, 2005, 13, 9460.

[102] Maruyama, T.; Okumura, T.; Sakamoto, S.; Miura, K.; Nishimoto, Y.; Arai, S. GaInAsP/InP membrane BH- DFB lasers directly bonded on SOI substrate. Opt. Express, 2006, 14, 8184.

[103] Van Campenhout, J.; Rojo-Romeo, P.; Regreny, P.; Seassal, C.; Van Thourhout, D.; Verstuyft, S.; Di Cioccio, L.; Fedeli, J-M.; Lagahe, C.; Baets, R. Electrically pumped InP-based microdisk lasers integrated with a nanophotonic silicon-on-insulator waveguide circuit. Opt. Express, 2007, 15, 6744.

[104] Roelkens, G.; Van Campenhout, J.; Brouckaert, J.; Van Thourhout, D.; Baets, R.; Rojo Romeo, P.; Regreny, P.; Kazmierczak, A.; Seassal, C.; Letartre, X.; Hollinger, G.; Fedeli, J.M.; Di Cioccio, L.; Lagahe-Blanchard, C. III-V/Si photonics by die-to-wafer bonding. Mater. Today, 2007, 10, 36.

[105] Zahler, J.M.; Ahn, C-G.; Zaghi, S.; Atwater, H.A.; Chu, C.; Iles, P. Ge layer transfer to $\mathrm{Si}$ for photovoltaic applications. Thin Solid Films, 2002, 403-404, 558.

[106] Akatsu, T.; Deguet, C.; Sanchez, L.; Allibert, F.; Rouchon, D.; Signamarcheix, T.; Richtarch, C.; Boussagol, A.; Loup, V.; Mazen, F.; Hartmann, J-M.; Campidelli, Y.; Clavelier, L.; Letertre, F.; Kernevez, N.; Mazure, C. Germanium-on-insulator (GeOI) substrates - a novel engineered substrate for future high performance devices. Mater. Sci. Semiconductor Process., 2006, 9 , 444.

[107] Deguet, C.; C Sanchez, L.; Akatsu, T.; Allibert, F.; Dechamp, J.; Madeira, F.; Mazen, F.; Tauzin, A.; Loup, V.; Richtarch, C.; Mercier, D.; Signamarcheix, T.; Letertre, F.; Depuydt, B.; Kernevez, N. Fabrication and characterisation of $200 \mathrm{~mm}$ germanium-on-insulator (GeOI) substrates made from bulk germanium. Electron. Lett., 2006, 42, 415.

[108] Depuydt, B.; Theuwis, A.; Romandic, I. Germanium: From the first application of Czochralski crystal growth to large diameter dislocation-free wafers. Mater. Sci. Semiconductor Process., 2006 9, 437.

[109] Derluyn, J.; Dessein, K.; Flamand, G.; Mols, Y.; Poortmans, J.; Borghs, G.; Moerman, I. Comparison of MOVPE grown GaAs solar cells using different substrates and group-V precursors. $J$. Cryst. Growth, 2003, 247, 237.

[110] Maeda, T.; Ikeda, K.; Nakaharai, S.; Tezuka, T.; Sugiyama, N.; Moriyama, Y.; Takagi, S. High mobility Ge-on-Insulator p-channel MOSFETs using $\mathrm{Pt}$ germanide Schottky source/drain. IEEE Electron Device Lett., 2005, 26, 102.

[111] Yu, D.S.; Kao, H.L.; Chin, A.; McAlister, S.P. Performance and potential of germanium on insulator field-effect transistors. J. Vac. Sci. Technol., A, 2006, 24, 690.

[112] Le Royer, C.; Clavelier, L.; Tabone, C.; Deguet, C.; Sanchez, L.; Hartmann, J-M.; Roure, M-C.; Grampeix, H.; Deleonibus, S. $0.12 \mu \mathrm{m}$ p-MOSFETs with High-k and Metal Gate Fabricated in a Si Process Line on $200 \mathrm{~mm}$ GeOI Wafers. In 37th European Solid State Device Research Conference, ESSDERC, 2007, p. 458. 
[113] Thomas, S.G.; Johnson, E.S.; Tracy, C.; Maniar, P.; Li, X.; Roof, B.; Hartmann, Q.; Ahmari, D.A. Fabrication and Characterization of InGaP/GaAs Heterojunction Bipolar Transistors on GOI Substrates. IEEE Electron Device Lett., 2005, 26, 438.

[114] Archer, M.J.; Law, D.C.; Mesropian, S.; Haddad, M.; Fetzer, C.M.; Ackerman, A.C.; Ladous, C.; King, R.R.; Atwater, H.A. $\mathrm{GaInP} / \mathrm{GaAs}$ dual junction solar cells on $\mathrm{Ge} / \mathrm{Si}$ epitaxial templates. Appl. Phys. Lett., 2008, 92, 103503.

[115] Taraschi, G.; Pitera, A.J.; Fitzgerald, E.A. Strained Si, SiGe, and Ge on-insulator: review of wafer bonding fabrication techniques. Solid-State Electron., 2004, 48, 1297.

[116] Dohrman, C.L.; Chilukuri, K.; Isaacson, D.M.; Lee, M.L.; Fitzgerald, E.A. Fabrication of silicon on lattice-engineered substrate (SOLES) as a platform for monolithic integration of CMOS and optoelectronic devices. Mater. Sci. Eng. B, 2006, 135, 235.

[117] Chilukuri, K.; Mori, M.J.; Dohrman, C.L.; Fitzgerald, E.A. Monolithic CMOS-compatible AlGaInP visible LED arrays on silicon on lattice-engineered substrates (SOLES). Semiconductor Sci. Technol., 2007, 22, 29.

[118] Yang, J.; Bhattacharya, P.; Mi, Z. High-performance $\operatorname{In}_{0.5} \mathrm{Ga}_{0.5} \mathrm{As} /$ GaAs quantum-dot lasers on silicon with multiple-layer quantumdot dislocation filters. IEEE Trans. Electron. Devices, 2007, 54, 2849.

[119] Yang, J.; Bhattacharya, P. Integration of epitaxially-grown InGaAs/GaAs quantum dot lasers with hydrogenated amorphous silicon waveguides on silicon. Opt. Express, 2008, 16, 5136.

[120] Fang, A.W.; Lively, E.; Kuo, Y-H.; Liang, D.; Bowers, J.E. A distributed feedback silicon evanescent laser. Opt. Express, 2008, $16,4413$.

[121] Datta S.; Dewey G.; Fastenau J.M.; Hudait M.K.; Loubychev D.; Liu W.K.; Radosavljevic M.; Rachmady W.; Chau R. Ultrahighspeed $0.5 \mathrm{~V}$ supply voltage $\operatorname{In}_{0.7} \mathrm{Ga}_{0.3} \mathrm{As}$ quantum-well transi-stors on silicon substrate. IEEE Electron Device Lett., 2007, 28, 685.

[122] Hudait, M.K.; Dewey, G.; Datta, S.; Fastenau, J.M.; Kavalieros, J.; Liu, W.K.; Lubyshev, D.; Pillarisetty, R.; Rachmady, W.; Radosavljevic, M.; Rakshit, T.; Chau, R. Heterogeneous integration of enhancement mode $\mathrm{In}_{0.7} \mathrm{Ga}_{0.3}$ as quantum well transi-stor on silicon substrate using thin $(<2 \mathrm{~mm})$ Composite Buffer Architecture for High-Speed and Low-voltage (0.5V) Logic Applications. Electron Devices Meeting, IEDM 2007. IEEE International 10-12 Dec. 2007, p. 625.

[123] Griffith, Z.; Lind, E.; Rodwell, M.J.W.; Fang, X-M.; Loubychev, D.; Wu, Y.; Fastenau, J.M.; Liu, AW.K. Sub-300 nm InGaAs/InP Type-I DHBTs with a $150 \mathrm{~nm}$ collector, $30 \mathrm{~nm}$ base demonstrating $755 \mathrm{GHz}$ fmax and $416 \mathrm{GHz} \tilde{\mathrm{ft}}$. In 19th Indium Phosphide and Related Materials, Matsue, Japan, May 14 - 18, 2007, p. 403.
[124] Hoke, W.E.; Kennedy, T.D.; Torabi, A.; Whelan, C.S.; Marsh, P.F.; Leoni, R.E.; Xu, C.; Hsieh, K.C. High indium metamorphic HEMT on a GaAs substrate. J. Cryst. Growth, 2003, 251, 827.

[125] Lubyshev, D.; Fastenau, J.M.; Fang, X-M.; Wu, Y.; Doss, C.; Snyder, A.; Liu, W.K.; Lamb, M.S.M.; Bals, S.; Song, C. Comparison of As- and P-based metamorphic buffers for high performance InP heterojunction bipolar transistor and high electron mobility transistor applications. J. Vac. Sci. Technol. B, 2004, 22, 1565 .

[126] Lubyshev, D.; Liu, W.K.; Stewart, T.R.; Cornfeld, A.B.; Fang, XM.; Xu, X.; Specht, P.; Kisielowski, C.; Naidenkova, M.; Goorsky, M.S.; Whelan, C.S.; Hoke, W.E.; Marsh, P.F.; Millunchick, J.M.; Svensson, S.P. Strain relaxation and dislocation filtering in metamorphic high electron mobility transistor structures grown on GaAs substrates. J. Vac. Sci. Technol. B, 2001, 19, 1510.

[127] Wu, Y.Q.; Xu, M.; Ye, P.D.; Cheng, Z.; Li, J.; Park, J-S.; Hydrick, J.; Bai, J.; Carroll, M.; Fiorenza, J.G.; Lochtefeld, A. Atomic-layerdeposited $\mathrm{Al}_{2} \mathrm{O}_{3} \quad / \mathrm{GaAs}$ metal-oxide-semiconductor field-effect transistor on $\mathrm{Si}$ substrate using aspect ratio trapping technique. Appl. Phys. Lett., 2008, 93, 242106.

[128] International Technology Roadmap for Semiconductors; 2007 ed; Process integration, devices, and structures http://public.itrs.net/Links/2007ITRS/2007_Chapters/2007_PIDS.p df, p. 29.

[129] Takagi, S.; Irisawa, T.; Tezuka, T.; Numata, T.; Nakaharai, S.; Hirashita, N.; Moriyama, Y.; Usuda, K.; Toyoda, E.; Dissanayake, S.; Shichijo, M.; Nakane, R.; Sugahara, S.; Takenaka, M.; Sugiyama, N. Carrier-transport-enhanced channel CMOS for improved power consumption and performance. IEEE Trans. Electron Devices, 2008, 55, 21.

[130] Chau, R.; Doczy, M.; Doyle, B.; Datta, S.; Dewey, G.; Kavalieros, J.; Jin, B.; Metz, M.; Majumdar, A.; Radosavljevic, M. Advanced CMOS Transistors in the Nanotechnology Era for HighPerformance, Low-Power Logic Applications. In Proceedings of 7th International Conference on Solid-State and Integrated Circuits Technology, 2004, vol. 1, p. 26.

[131] Antoniadis, D.A.; Aberg, I.; Chleirigh, C.N.; Nayfeh, O.M.; Khakifirooz, A.; Hoyt, J.L. Continuous MOSFET performance increase with device scaling: the role of strain and channel material innovations. IBM J. Res. Dev., 2006, 50, 363.

[132] Chau, R.; Datta, S.; Majumdar, A. Opportunities and Challenges of III-V Nanoelectronics for Future High-Speed, Low-Power Logic Applications. In Compound Semiconductor Integrated Circuit Symposium CSIC '05. IEEE, 2005, 17.

[133] Wu, M.; Alivov, Y.I.; Morkoc, H. High-k dielectrics and advanced channel concepts for Si MOSFET. J. Mater Sci. Mater Electron, 2008, 19, 915 .

(C) Bolkhovityanov and Pchelyakov; Licensee Bentham Open.

This is an open access article licensed under the terms of the Creative Commons Attribution Non-Commercial License (http://creativecommons.org/licenses/by-nc/3.0/) which permits unrestricted, non-commercial use, distribution and reproduction in any medium, provided the work is properly cited. 